Portland State University

PDXScholar

8-1-1969

\title{
A general study of tests and testing with special emphasis on concepts, controversy, and teaching ideas applicable at the first grade level
}

Jean I. Dimick

Portland State University

Follow this and additional works at: https://pdxscholar.library.pdx.edu/open_access_etds Let us know how access to this document benefits you.

\section{Recommended Citation}

Dimick, Jean I., "A general study of tests and testing with special emphasis on concepts, controversy, and teaching ideas applicable at the first grade level" (1969). Dissertations and Theses. Paper 930.

https://doi.org/10.15760/etd.930

This Thesis is brought to you for free and open access. It has been accepted for inclusion in Dissertations and Theses by an authorized administrator of PDXScholar. Please contact us if we can make this document more accessible: pdxscholar@pdx.edu. 
AN ABSTRACT OF THE THESIS OF Jean I. Dimick for the Master of Science in Elementary Education presented August 6, 1969.

Title: A General Study of Tests and Testing With Special Emphasis on Concepts, Controversy, and Teaching Ideas Applicable at the First Grade Level.

APPROVED BY MEMBERS OF THE THESIS COMMITTEE:

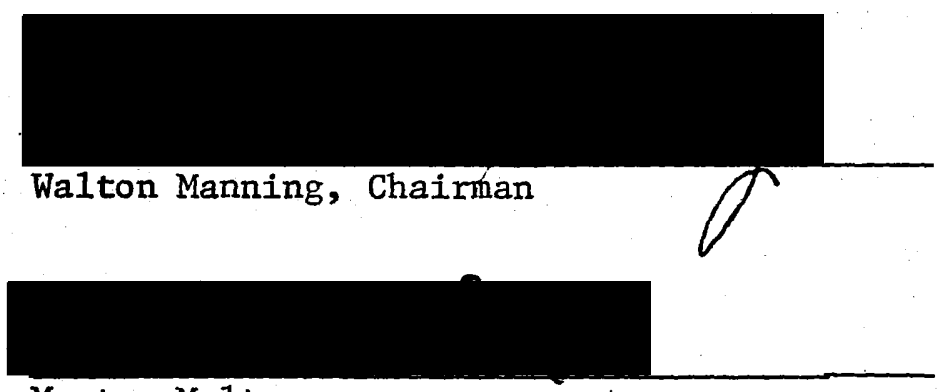

Morton Malter

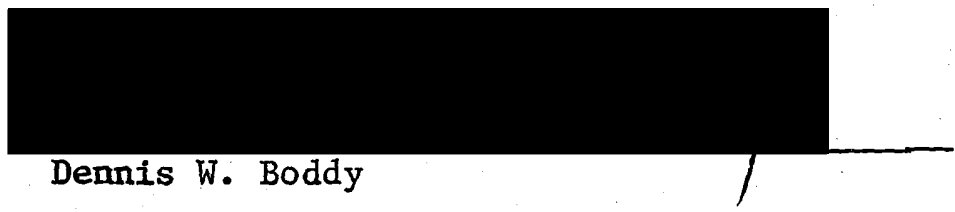

A general study of testing with special focus on, and analysis of, tests being used in the primary grades by selected cities; the controversy concerning aptitude and intelligence testing as it applies particularly to genetic factors and race; and the identification and selection of ideas which would be of value to a first grade teacher seeking diverse and unusual ways to discover abilities and aptitudes in first grade children. Study covers in detail some of the controversy about racial intelligence as it concerns black and white Americans starting with interpretations and controversies that occurred after World War I, and also with current controversy about the same topic 
(racial intelligence) and the relative importance of genetic and environmental factors in the interpretation of test scores. Agreement among various authorities whe have contrasting ideas on genetic factors and their influence is discussed along two basic lines of agreement: the belief that almost all children can learn basic skills, and that this learning can best be accomplished if diverse learning approaches are used. Study concludes with an identification of, and detailed description of teaching techniques which could be used by a first grade teacher who sought in diverse ways to discover aptitudes and abilities in her children. 
A GENERAL STUDY OF TESTS AND TESTING WITH SPECIAL EMPHASIS ON CONCEPTS, CONTROVERSY, AND TEACHING IDEAS APPLICABLE AT THE FIRST GRADE LEVEL

$$
\text { by }
$$

Jean I. Dimick

A thesis submitted in partial fulfillment of the requirements for the degree of

MASTER OF SCIENCE

in

ELEMENTARY EDUCATION

Portland State University

1969 
TO THE OFFICE OF GRADUATE STUDIES:

The members of the committee approve the thesis of

Jean I. Dimick presented August 6, 1969.

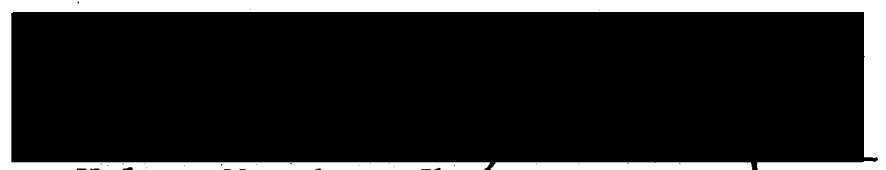

Walton Manning, Chalrman

j

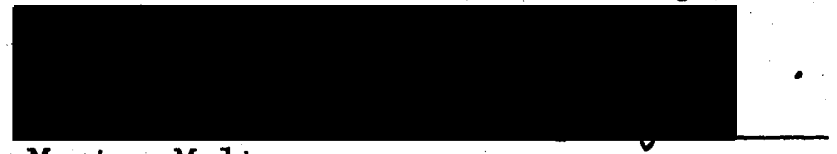

Morton Malter

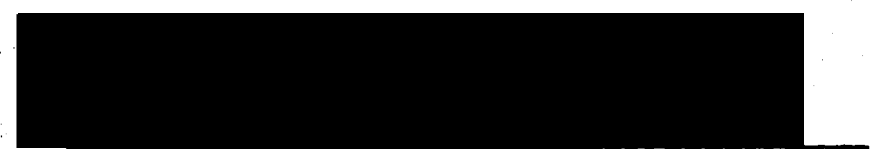

Dennis W. Boddy

7

APPROVED:

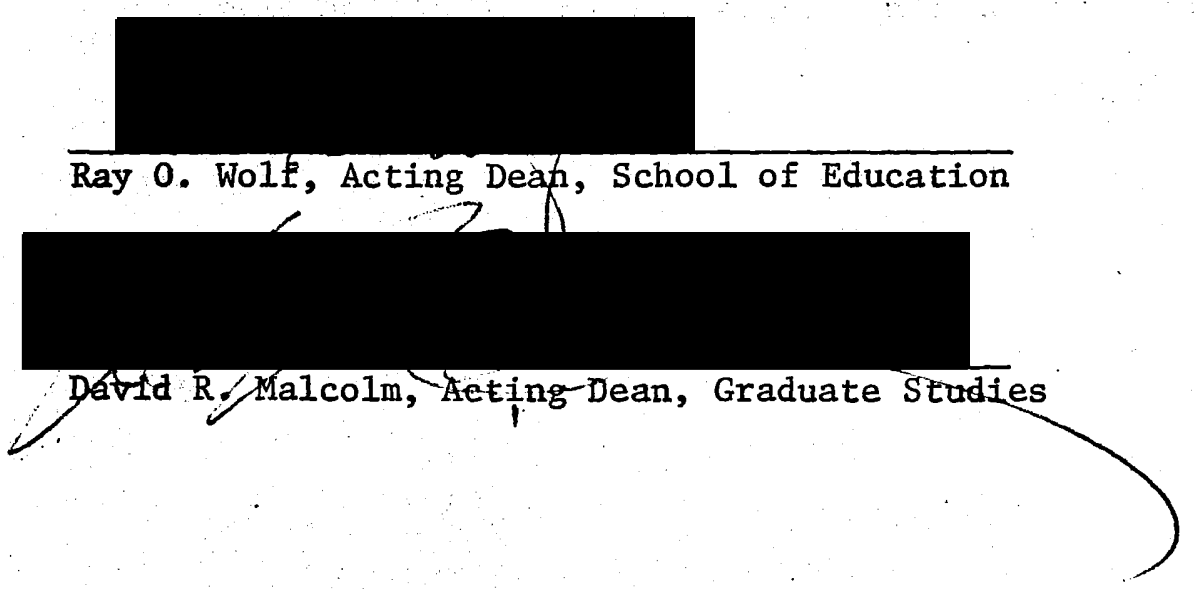




\section{ACKNOWLEDGMENTS}

The writer wishes to acknowledge with sincere appreciation the help of numerous professors who aroused enthusiasm for learning in their classes and a desire to learn in this individual. It was the efforts of these professors which enabled the writer to see learning as part of a process of integration which crossed subject lines and the need to transfer and apply what was learned to one's own behavior in general and to teaching in particular.

The writer also wishes to thank the members of the committee who read this thesis, Dr. Morton Malter, and Dr. Dennis W. Boddy, and her chairman, Dr. Walton Manning who challenged and analyzed the work line by line and paragraph by paragraph. His time and intelligent efforts are deeply appreciated as a vital and necessary part of the total project. A special thanks must also be given to the diligent editing and typing efforts of Barbara Wiegele who made the project into a document of correct form and appearance.

The writer finally wishes to acknowledge the encouragement and inspiration of her parents, Norm and Winefred, for without their help there would have been no basic degree, nor any interest in learning as a process that must go on as long as one is alive and seeking to become a better person. 
TABLE OF CONTENTS

\section{PAGE}

ACKNOWLEDGEMENTS

iii CHAPTER

I INTRODUCTION ............. 1

II A GENERAL LOOK AT TESTS AND TESTING . . . . 10

III INTELLIGENCE, COMPENSATORY EDUCATION, AND SCHOOL ACHIEVEMENT ......... 40

IV CONCLUDING ACTIVITIES AND SUMMARY . . . . 58

BIBLIOGRAPHY . . . . . . . . . . . 87

APPENDIX . . . . . . . . . . . . . 93 


\section{CHAPTER I}

\section{INTRODUCTION}

\section{Origin and Nature of the Problem}

A graduate student in any specialized discipline might have a relatively simple objective. He might have one topic which he wished to study in depth and then follow up that topic with research which attempted an application of some phase of the topic. A graduate student in teacher education, however, has a problem which if not more complex has many more facets and directions in which to go. Should such a student wish to do original research he might find this almost impossible in that a vast quantity of educational research of all types and kinds can be found in almost any field concerning learners and learning, materials and methods, theories and practices, goals and objectives, skills and concepts, all of which are both personal and institutional at least in some degree.

Early in one's experience as a student of teaching it is possible to conclude that teaching is merely a position which requires some knowledge of subject matter, a bag of various and assorted tricks and devices to make this knowledge available to the young, and then practice in the application; hopefully, practice that will be analyzed and then reconstructed in an effort to make the next practice more productive for teacher, learner, and society. It is also possible, however, to conclude that Barzun $(8, p, 3)$ was mistaken when he referred to education as "the great Sahara desert of the mind," (he had reference to the study of education) and that the study of teaching as a pro- 
fession involves a multitude of opportunities and challenges of a magnitude sufficient to interest any individual. And such interest could be as challenging intellectually as the individual chose to make 1t. Thus this "desert of the mind" type of appellation could be made to bloom and produce; if the proper attitude, organization, and selection became a self-propelled part of the process.

Believing that the study of teaching was both interesting and challenging, a student would still be faced with the problem of selecting what to know from a vast amount of material no one could possibly do anything but sample. Having realized the problem of selection of something from much, and an equally perplexing problem of separating research from opinion, this graduate student was advised that in graduate work certain broad general guidelines could be followed. Among these were the following:

1. To seek a broad general knowledge about as many things as possible because teachers must deal on some kind of a rational basis with students and other persons who have collective knowledge and questions about most of the disciplines and major and minor areas of what man has learned about himself and his universe.

2. That narrowing one's aim professionally toward a particular area or level would enable one to become better informed and more professionally competent in the level selected.

3. In course selection and in topics pursued attempt to find one current and relevant topic to be studied in sufficient 
depth so as to be able to claim some degree of expertise among one's peers on at least this one topic.

4. Finally to narrow what one was learning sufficiently so as to be able to apply what had been learned to one's own teaching in as practical, creative, intelligent, and usable form as might be possible.

\section{Statement of the Problem}

This study was designed as a follow up of the previous guidelines listed above. This design had as its final goal the writing of a thesis which would cover points pursued along the route of graduate study and culminate in a final portion which would deal directly with ideas that could be used in teaching first grade children.

Portland State is an institution which sets forth as one of its primary goals an acquisition of a liberal education for all students. Those students who are majoring in elementary education are required to have two areas of subject matter as areas of concentration. These requirements plus additional required sequences in areas such as physical and biological science, music, art, geography, sociology (or anthropology), literature, and composition are all nine hour requirements for each separate subject. In addition six hours of history (or government) and six hours of mathematics constitute a quantity of liberal arts type education designed to develop a background of broad, general education. These requirements plus additional hours in two 
areas which actually constitute minors and the professional requirements constitute what would appear to be a well-rounded undergraduate curriculum.

A graduate student at Portland State (who also did his undergraduate work at the same institution) thus is in an excellent position to explore the types of guidelines outlined for this student. In an effort to follow those guidelines and develop some type of a comprehensive plan leading to a thesis the following points were selected and followed :

1. In terms of the times and broad general knowledge previously acquired, a three sequence course in the history of science was selected as of most value in becoming better prepared to deal with current and persistent topics such as sex education, the origin of the species man, and problems man has created in his physical environment.

2. The narrowing of professional aims was accomplished by deciding that the area of primary interest to be explored was to be the primary grades with special emphasis on first grade and learning problems encountered by those seeking initial success in formal learning irrespective of age or grade.

3. As a current topic relevant to the present school situation the special learning problems of the disadvantaged was selected with special emphasis on the possible relationship between intelligence and achievement and environment and achievement with particular respect to those disadvantaged 
who were black Americans. The study of this topic led to an examination of what part, if any, race did play in Intelligence; which, of necessity, involved taking a general look at testing for intelligence, tests used to measure achievement, and problems that contributed to success or failure in learning of all types and kinds of students but particularly the disadvantaged.

4. A natural outcome of such study as listed above leads to the conclusion that irrespective of what part, if any, race plays in scores earned on intelligence and achievement tests, children of all types and kinds from various racial and ethnic backgrounds and with varying degrees of racial and environmental advantages and disadvantages do experience problems of school success. Narrowing this down to what is essentially the first formal school year, first grade, it became clear that unique and unusual teaching techniques and ideas could be developed which could be used to challenge and motivate various types and kinds of children drawn from various (and perhaps as yet unknown) positions on the range of ability, aptitude, interest, and experience. It was the development of such ideas and activities which constitute the culminating and final portion of this thesis.

\section{Purpose of the Study}

This study or project seeks to establish a general background of 
knowledge of the testing movement and some of the types and kinds of uses made of tests. In order to make some kind of an applicative analysis of a general type of test a special effort will be made to study the possible relationship which might exist between black Americans and scores on intelligence tests. Information will be gathered from various selected school districts in the United States as to uses they make of tests in the primary grades and what tests in particular are used by these school districts for first grade children.

After general information of the nature described has been gathered then a more specific analysis will be made of achievement type tests in that what they are attempting to measure is presumably a sampling drawn from what schools use in the way of materials and what schools claim to teach. Using the information gained on these tests and also on any unique or unusual test or test items discovered, the project will then move into its final phase; the search for and the identification of specific ideas and lessons which can be presented in an actual classroom of first grade children.

\section{Limitations of the Study}

The first and perhaps the most binding limitation of this study is that it is more of a project than a study. Certainly it is not a research study in the ordinary use of the word although what is being looked at will include some articles which will be research, some called research which is merely opinion, and finally some material that is clearly opinion and judgment. 
It might aptly be listed as a limitation that this project or study should avoid both recent criticism of much that is done in education because it fails to follow sound procedures of research and also to fail to follow recommendations that seem valid as to what type of design good research should follow.

Gage, writing on the general trends in research says,

Whatever may have been its status in an earlier period, the term theoretic has an attractive connotation now. If it once suggested the opposite of "practical," it is now recognized as referring to the fundamental basis of practice. (27, pp. 94-96)

Gage then describes how graduate and other students seem to avoid theory and prefer other methods of collecting and analyzing data. He quotes Lane as follows:

There is no more arcane term in general use among. humanists and social scientists than the term "theory." To the graduate student it carries with it a modest prestige suggesting that a person who is a theorist is brighter, deals with "deeper" and more complex material, and has insights which others who identify themselves differently do not have. (27, pp. 94-96)

It seems that in the sense that Gage is describing theory and in the criticism made by Lane, that this project does not completely avoid the use of a theory to follow no matter how ill-defined it might be because of its general-to-highly-specific approach. It also appears that in the loosest sense of the word this project follows a paradigm type of approach. Such a statement is based on acceptance of Gage's idea that paradigms are not "theories; rather ways of thinking or patterns for research that, when carried out can lead to the development of theory. Paradigms derive their usefulness from their generality." (27, p. 96) The final sentence has meaning for this 
study in that it will be general though finally becoming very specific (and thus practica1); but no well-defined theory is being followed and it is highly unlikely that any defensible theory can be developed from the completed project. This then constitutes a modern but valid 1imitation. Other limitations exist of a more normal nature; materials selected, judgments made, and in formulation of ideas which presumably will work as designed.

Value and Importance of the Project

The major value of this study is peculiarly personal. The general knowledge and study will contribute mostly to the individual doing the study, and the specific lessons which are the culminating aspect will provide one individual with unique things to try and do which hopefully will make teaching richer and more productive in one teaching station.

This, however, is a time when focus (and rightly so) is switching to the individual and his role in finding relevancy in a college and university situation. Whatever its limitations and they are admittedly crucial, this study and project had an aim of unifying some of the processes and concepts learned as an undergraduate student and in graduate study and to pull some of these learnings together into a project that would be relevant to the individual student and lead to possible better materials and methods of teaching in his own teaching situation. In the sense that everything done in the study is being done to further the above it should be of value and it is possible that 
in the lessons developed and the techniques and ideas that grow out of this project there might be found activities of interest not only to one individual but to other individuals who are also teaching first grade and perhaps even to the school district in which it is being written...... the Portland Public Schools. 


\section{CHAPTER IT}

A GENERAL LOOK AT TESTS AND TESTING

\section{Historical Development}

The Encyclopedia of Educational Research (25, pp. 1502-1515)

is an excellent source of background information on the development of tests and examinations. Separate sections on various types of tests (aptitude, intelligence...) are found and some will be examined later. This particular portion is concerned with the historical development of tests and examinations in general with no difference being made in definition of the two terms (i.e., test, examination) which are defined in the Encyclopedia as "a series of questions or tasks designed to measure the knowledge or skill of an individual."

Written examinations were traced by Kuo (25, p. 1503) back to ancient China as far as the twenty-third century B.C. Ancient China developed a system of competitive examinations which helped establish a precedent for using examinations as a basis for determining whom would be employed and promoted. European universities from their beginning emphasized examinations as the basis for the awarding of honors and degrees. The Cambridge Tripos is an example of such an examination.

Horace Mann was responsible for an interesting development in testing which is about to be applied nationally. Mann and educators had engaged in a controversy about the quality of performance and education in the Boston Schools. A uniform set of tests was devised 
and administered uniformly to a random sample of Boston pupils. Test results indicated a poor quality of education, and these were challenged by professional educators. At any rate the arguments advanced by Mann are presently included in currently used tests and will be used in tests developed for the national assessment of the quality of education, a movement spear-headed by the United States Office of Education and the American Council on Education and resisted by various professional groups including some school superintendents. Mann's recommended practices still being followed include substitution of written for oral examinations, the use of a large number of specific questions in place of fewer general questions, and a search for more objective standards of educational achievement. (25)

Reformers often seem to be responsible for new developments in all phases of education and sometimes these reformers (like Mann) are not a part of the professional establishment of education. Another reformer, J. M. Rice, developed some of the first essentially objective tests for his use in surveys of school accomplishment. Rice was one of the pioneers of the scientific movement in education which led to scores of research studies on the statistical properties of all kinds of tests. In the main these studies were of three types: construction, use, and scoring of objective tests and essay tests, and the contrasting effectiveness of the two types in measurement, evaluation, prediction, and placement. Results of these studies led to an increasing use of objective type testing until recently when such tests have themselves been under attack. 
Controversies involving testing methods or even of examinations themselves are not new but it is through examination of some of these arguments that one might gain some better understanding of aspects with which this project is concerned. The current criticism, for example, about difficulties of essay type grading (as in written compositions) may lead one to conclude as does Riemer (in a new attack on what he, Riemer calls the murder of the second $R$, writing) that no grading at all is the best answer. (18, p. 9) On the other hand there has been a new scientific attempt to up-grade the quality of grading of written answers. This up-grading has been spear-headed by the College Entrance Examination Board, and the Educational Testing Service. Writing a review of Riemer's new attack on writing, the reviewer says:

In spite of a number of statements to the contrary, good writing is both definable and recognizable. Educational Testing Service has proved again and again that a group of readers, consisting of college composition teachers and public and private secondary English teachers, can agree quite readily on the rating of a specific paper. They will not agree so readily on the specific strengths and weaknesses of that paper, and perhaps no rating would ever be unanimous, but that does not deny the importance of their general agreement. As a matter of interest, the Educational Testing Service reader group, at any one time, includes a number of people who have written books or series of books on the teaching of composition which show no great agreement on method or approach. If their books have something in common, it is the recognition that writing is extremely important and that successful writing is almost always very hard work. (18, pp. 11-12)

A review of a variety of sources on measurement and evaluation reveals a commonality among recommendations concerning tests irrespective of the type. $(3,21,22,24,43,69)$ 
A summary of these common factors would attempt to identify and analyze the following:

1. What is the appropriate form of test to use? This question of course cannot be answered until one first establishes what it is that is to be measured and what materials are available to choose between.

2. What are the necessary preparations to make before selection of test items to use. Almost anything measured is complex and has many facets, parts, ideas, concepts, and skills. There is also at least one significant difference in the identification of a given skill, idea, and/or concept and its application. What is to be selected must then in most situations involve some kind of a sample from a large supply available (in terms of these ideas, materials, etc.) and some attempt to find out to what extent those items selected actually differentiate between those who know and those who do not know as much about whatever it is to be tested.

3. Analysis of test results in detail. This involves not only the possible weighting of items but an analysis of why some types of learners or test takers did one thing on the test and its individual parts and why other similar types of test takers did something different. This analysis can lead to a variety of suggestions for improvement and perhaps even for re-weighting as well as remodeling of the test itself.

4. What use can be made of the results. Here the test maker, 
the test analyzer, the teacher, and the test taker himself might come up with a variety of differing conclusions about the same kind of a score. It is in the use of test results (or misuse) that some of the most complex and controversial problems have developed.

Intelligence Tests. An Example of Complexity and Controversy as Demonstrated by Racial Intelligence Research

The above points may seem simple but like many simple questions or statements they are extremely difficult to answer and apply. In no instance is this difficulty more evident than in the attempts to measure intelligence. In the first place one cannot answer the first question as to what is the appropriate test to use without trying to arrive at some definition of what intelligence is. Manning (45) found fifteen different definitions of intelligence ranging from Terman's "intelligence is the ability to think in terms of abstract ideas," to Weschler's "intelligence is the capacity to act purposefully, think rationally, and deal effectively with environment." In between were such definitions as the "ability to break old habits and form new ones," and, "intelligence is the capacity to acquire capacity." Not only is intelligence one of the most complex and controversial of all types of testing but in its use with racial groups it has been and continues to be an example of some of the most significant and acute problems facing any student who wishes to know more about teaching and learning and to use test results as a guide for action. 
Bagley (5, pp. 34-46) in one of the clearest and most persuasive chapters of a highly important (though old) book, outlines his objections to intelligence tests and the fallacy of believing that such tests actually measure native intelligence or capacity. Rather he believes that whatever was being measured had been acquired in the environment and that the environment could be altered and when altered, the intelligence score would be changed. That Bagley's book is older (1925) and on a topic tremendously studied and researched in recent times has nothing at all to do with the wisdom of what he wrote. What he wrote (more about this later) was not only pertinent then but is applicable today. Examples of this are evidenced by: his definition of democracy as "the collective supremacy of the common man;" his many expressions of faith in the masses of people and what education could do for them and for democracy-- "to endow the masses with genius is biologically impossible; but to endow the masses with the fruits of genius is both educationally possible and socially most profitable;" "The mental tests will render a gratuitous and disastrous disservice if they encourage in the teacher the conviction that the illumination of the common minds is either an impossible or a relatively unimportant task."

It appears that so far it has been demonstrated that intelligence is difficult to design, that what it measures in terms of what one is and what one acquires is in dispute, and that education can be of value both to democracy and in the development of individuals irrespective of their scores on mental tests. One definition (source unknown) that is 
widely heard for intelligence is simply this: "intelligence is whatever It is that intelligence tests test." In this paper it will be assumed that intelligence test scores do reveal something about the individual and his capacity as well as an indication of what he has achieved. What part or portion of the score represents one, the other, or a combination of both is assumed to be unknown, but it is proposed to examine and compare the scores made by Negroes and whites in the United States and then evaluate and describe what experts say about the possible role that environment played in these scores.

A recent issue of Time Magazine containing an essay on "Race and Ability" (70, pp. 46-47) quotes anthropologist Morton Fried as saying that debate over racial differences in intelligence is not scientific but merely "means lifting in the public eye the status of studies otherwise disqualified and rejected by science." Time, however, (as do many popular and scholarly journals) continues to discuss the topic and make such comparisons. Among other things it says that the Negro generally scores (on the average) fifteen to twenty points less than whites on I.Q. tests. It goes on to say:

The results of World War I Alpha intelligence tests have frequently been cited as evidence of the Negro's mental inferiority, since the Negro soldier invariably ranked below the white soldier on a state-by-state basis. But the same test results can be used in another way to demonstrate that Negroes are smarter than whites. On the Alpha tests, for instance, Negro solders from the Northern state of Ohio outscored whites from eleven Southern states. Beyond this, it could be inferred from the tests that Northern whites are superior to Southern whites, because they almost always did better. (70, p. 47)

When the above was read, the writer was just starting research on 
this topic and the statistics cited above were accepted without question as an ideal piece of evidence that the Negro was as intelligent as the white, and given a better environment (such as in the North), he would do as well as the white (and he did better than whites In the South). Bagley, however, made the first analytical study of these comparative scores earned on the Alpha test in World War I not for the basis of combatting any racial theories, but in an attempt to show that the quality and kind of education one had would profoundly influence scores on an intelligence test.

Using official War Department tables, Bagley (5, p. 125) showed that 1iterate Negroes from Illinois achieved a median score above the median score of the literate whites from nine Southern states; that the 1iterate Negroes from New York surpassed the literate whites from five Southern states; that the literate Negroes from Pennsylvania surpassed the literate whites from two Southern states; while for all Northern Negroes reported, the median Alpha scores surpassed the median Alpha score for the whites of Mississippi, Kentucky, and Arkansas.

Garrett (63, pp. 182-184), using different methods of comparing the same scores found that even where Northern Negroes exceeded Southern whites that they were just as far behind Northern whites as Southern Negroes were below Southern whites. The same source (63, p. 182) pointed out that in so far as the Ohio scores were concerned only 152 cases were recorded, hardly enough to be considered valid unless they were a representative sample which no one claimed them to be. A wide variety of authorities have written about and analyzed 
comparative ratings of Negroes and whites on test results but the most comprehensive collection of data is found in a book by Audrey Mary Shuey. This book has been widely attacked as segregationist propaganda but evidently no one has questioned the validity or accuracy of the studies Dr. Shuey has used in the book; (a foreword for the book was written by Dr. Henry E. Garrett, a prominent member of the scholars who are psychologists, and himself a former president of the American Psychological Association).

Dr. Shuey reviews nine studies comparing mental test scores of white and Negro young children. She explained the findings (which revealed that young Negroes earned scores lower but closer to those of young white children than comparative scores on white and Negro in older age brackets) by stating her hypotheses as follows:

Tests at the school level become increasingly verbal and involve more abstractions and generalizations; the mental growth curves need not be the same for the two races; at the two to six year levels the IQ is less affected by either enriching or constricting environment influences than during the school period. $(63, \mathrm{pp} \cdot 17)$

In later chapters Shuey (63) reviews comparative test data on school children given individual tests, non-verbal group tests, and verbal group tests. She also reviews comparative studies for high school and college students, Armed Forces, gifted, retarded, delinquents and criminals, racial hybrids, and those subjects classified under the title of selective migration.

Shuey, in selecting studies to be reviewed, examined some of the prominent surveys which had been analyzed by authors seeking to destroy the "myth" of racial superiority or inferiority as might be demonstrated 
by differing scores made by racial groups on various psychometric tests. Shuey (63) believed that the data did not support conclusions that some had apparently reached. Altogether she analyzed and used data covering a span of forty-four years, approximately 240 experimental studies were examined and some sixty tests were employed (63, p. 307). Consistently she found that Negroes scored significantly lower than whites even though there was an overlap and some Negro children earned scores higher than the white median scores. Results were practically consistent in showing an unexplained lower average and median scores for Negroes of all ages, backgrounds, and experiences and a heavy cluster of Negro scores near the bottom of the distribution of a scale of white scores. These results were unquestionably what caused her to conclude her book with the following:

The remarkable consistency in test results, whether they pertain to school or preschool children, to high school or college students, to drafts of World War I or World War II, to the gifted or the mentally deficient, the delinquent or criminal; the fact that the colored white differences are present not only in the rural South, and urban South, but in the border and northern areas; the fact that relatively small average differences are found between the IQ's of northern-born and southern-born Negro children in northern cities; the evidence that the tested differences appear to be greater for abstract than for practical and concrete problems; the evidence that the differences obtained are not due primarily to a lack of language skills, the colored averaging no better on non-verbal tests than on verbal tests; the fact that differences are reported in all studies in which the cultural environment of the whites appeared to be no more complex, rich, or stimulating than the environment of the Negroes; the fact that in many comparisons (including those in which the colored appeared to best advantage) the Negro subjects have been either more representative of their racial group or more highly 
selected than have the comparable white groups;

all point to the presence of some native

differences between Negroes and whites as

determined by intelligence tests. (63, p. 318)

Thus summed up is what one must conclude, probably, if he intends using intelligence test scores as reliable indicators of native intelligence and comparison of races by comparing scores. It is precisely at this point, however, that other scholars find answers which do not attribute differences in scores between black and white to racial differences. It is this point which is of interest to educators and sociologists as well as anthropologists, for even though there may well be [as Time Magazine (70) noted in talking with such scholars] a tendency to overstate a case against Negroes by bigots as well as a defensive posture on the part of others to deny research which might tend to establish racial differences, there must be valid and reasonable points to examine which explain rather than merely review and which base their starting point not on what one brings into the world in terms of native capacity, alone, but what effect differing environments have on individuals and groups, and what significance this must have for educators who are concerned with the educational goal of developing each individual citizen's potential to its fullest.

$$
\begin{aligned}
& \text { Authorities, Negro Environmental Disadvantages, and } \\
& \text { Explanations }
\end{aligned}
$$

It appears conclusive that Negroes in America consistently earn lower scores on psychometric tests than do whites and this cannot be 
explained by any known research about possible racial characteristics. There is opinion about racial characteristics which might account for lower Negro scores and this opinion is based on research but it remains opinion. There is also opinion which explains and accounts for the lower scores earned by Negroes and it is the purpose of this chapter to examine some of the reasons and ideas which are given by those who have written on this from a point of view not of condemnation of the Negro but of analysis and reasonable judgments, part of which are also based on research.

An article by Davis and Havighurst in the Scientific Monthly (20, pp. 418) attempts to answer the basic question of whether it is possible to measure intelligence. They point out the need for any test maker to have identified the cultures he is to test and said identification must include the basic component skills, concepts, and ideas which would be encountered in these cultures by any individual. According to these authors there are three distinctly different cultures in the United States based on behavior. These are: the common American cultural traits and behaviors, the various cultural behaviors of the different socio-economic groups, and the cultural patterns of the different "ethnic" or nationality groups. Davis and Havighurst see the necessity of attempting to control or equalize the cultural factors in a test and in the items a test uses.

Using research done by others (notably Tyler, Eells, Herrick, etc.) and their own studies they conclude that on many so-called intelligence tests an actual item analysis revealed that from 46 to 
100 percent of the items discriminated between the highest and lowest socio-economic classes and this discrimination was negative for the lower class and helpful to scores earned by children in the higher socioeconomic class. This discrimination was wide-spread among tests of socalled general intelligence and was evidenced by use of items that were supposedly part of the common culture but in fact were relatively unknown to the approximately "60 per cent of all Americans who grow up in the lower socio-economic groups" (20, p. 11). As an illustration of this fact an item involving identification of the definition (or concept) for the term "sonata" found more than 70 percent of the high economic group getting it right as against 28 percent of the lower economic group. On an item involving the concept of a "cutting tool," however, the high group had 76 percent right as compared to 79 percent of the low group who marked it correctly. If items could be found which were commonly offered as desirable things to learn in all of the cultures and sub-cultures found in the United States, then it might be possible to measure intelligence but no such tests appear to exist and the present tests and the present school curriculum appear to be geared toward middle-class commonalities, taught by middle-class oriented teachers.

It is obvious, both from reading even a limited amount of pertinent 1iterature, and talking with someone who has studied the problem at various levels and depths (44) that test scores of any group can be analyzed from three possible broad bases: the effect of native Inheritance, the effect of education, and the effect of environmental 
culture both within and without the school. It may be true, that little can be done to discover what biological differences exist in races (70) although it might be important for scholars to explore in depth the relationship, if any, between the fact that most Negroes (and other disadvantaged sub-groups) have parents who are unemployed and often poorly educated and adjusted to society, whereas a smaller number of children, particularly among the Negroes, come from parents who are college educated. (One of the smallest birth rates published by the 1960 census was the average of less than one child per marriage on the part of Negroes who were college educated).

If biological data is not available two aspects remain which concern the Negro; his education, and his environmental culture both within and without his school situation. It is these aspects which must be examined in an effort to explain or understand why he, the Negro continues even at this late date to lag (as a group) behind the white student when groups are compared to groups. (This is not to say that progress has not been made by the Negro; nor that some Negroes do not score higher than many whites; rather it is a mere statement of fact that Negro students still lag behind whites, north and south, east and west, as well as right here in our own city, Portland).

One of the first references used was Klineberg's initial comprehensive work on the Negro (39). In his book Klineberg lists stereotyped personality and culture traits that were associated with the Negro then and continue to be associated today by a number of people not all of whom are Southern. Among these characteristics (39, pp. 18-19) were 
such things as: low mentality, social gregariousness, emotional warmth, love of music and dance, low, double-standard (one for whites, one for own race) morals with high interest in sex, high emotional tone and interest in supernatural and superstitions where religion is concerned, low solidarity where family life is concerned with high frequency of common-law matings, high incidence of social disorder where law is concerned with resentment of white man's law, loudness, little race pride -- with white standards of beauty most accepted, and lack of cohesion and trust in own leaders with much intragroup conflict. (Though quoted by Klineberg these were prepared by Dr. Guy Johnson of the University of North Carolina and many of the ideas were drawn from Negroes writing about themselves).

One of the first stereotypes (44) concerns the idea that all Negroes were alike when they came to America as slaves. There is, of course, back of this view emotional as well as factual truth and untruth. An emotional and favorable history of the Negro which tends to glorify his virtues and omit his weaknesses is found in a book of Negro history by Arna Bontempts. The book is not written in a scholarly manner though it may well contain some factual material. The mood, however, is interesting and is best described by a poem written by Langston Hughes which the author includes (in fact the book is dedicated to Hughes) as a foreword $(12, \mathrm{p}, 2)$. This poem is as follows:

I've known rivers:

I've know rivers ancient as the world and older than the flow of human blood in human veins. My soul has grown deep like the rivers. 
I bathed in the Euphrates when dawns were young.

I built my hut near the Congo and it lulled me to sleep.

I looked upon the Nile and raised the pyramids above it.

I heard the singing of the Mississippi when Abe Lincoln went down to New Orleans, and I've seen its muddy bosom turn all golden in the sunset.

I've known rivers:

Ancient, dusky rivers.

My soul has grown deep like the rivers.

Manning (44) found that many studies show that the Negro does over-rationalize, over-dream, and waxes from a deep insecurity to an expressed overt and false pride where race is concerned. He found that even though 90 percent of Negro high school graduates in Florida made a score on the twelfth grade tests too low for admission to any of the segregated white colleges and universities (had they been white), that more than 90 percent indicated their intention to attend college and the most frequent reasons were to become a doctor, lawyer, engineer, or teacher.

Is the tendency to over-rationalize an indication of mental illness? Klineberg (39) included in his book an article on mental disease by Benjamin Malzberg. Malzberg (39, pp. 394-399) found that there are no mental diseases or disorders that are peculiar to Negroes. He did find, however, a much higher incidence of mental disease among Negroes and he attributed this not to a racial cause but rather to environmental (and familial) factors. Malzberg says:

These rates are due to the direct and indirect influence of conditions of life over which the Negro has as yet little control. Since the doors 
of economic opportunity are largely closed to him, he is compelled to pursue the heaviest, least desirable, and least remunerative occupations. His low income subjects him to correspondingly low levels of living.....homes in vicious and undesirable neighborhoods, unhygienic surroundings, overcrowding, undernourishment, together with the moral handicaps associated with such conditions of life. Surely, if mental life is an adaptation to environment, then the Negro is burdened, indeed. (39, p. 394)

Many authorities have written about the happiness adjustment (or lack of it) and self-image of the Negro. Baldwin (6) aptly describes the general attitude of hatred, frustration, and apathy which the social atmosphere of a Negro slum creates. Keller (37) in a study of self-concepts utilized a test which she gave to school children in a slum neighborhood in New York City. Keller found that these children had a low self-image and this lack of respect for one's self increased as the children grew older in the same environment. Many of these children were Negroes.

Coles (17), Moynihan (48), Silberman (65) and Cervantes (14) wrote about factors which help prevent the Negro from having a healthy attitude toward either himself or society. Faced as he often is without a known father the Negro faces a teacher who either openly or subtly represents a middle class set of values which tend to degrade those who are not spawned by a legalized marriage and to instill the belief that any able bodied man can, if he tries, find employment. In fact all of the factors described by these and other more recent authors differ only in detail from the description by Ginzberg in his book about the Negro potential. Ginzberg says: "Because inequality is so deep1y imbedded in the past, it will take considerable time, even under the 
best of circumstances for the Negro to gain equal status with the white population." (29, p. 96). He also points out the influence of family

life as follows:

Preparation for work begins in earliest childhood. When a young Negro has an opportunity to apply for a good job, his willingness to compete for it and his prospects of securing it depend on his earlier development and preparation for work. It is hard to exaggerate the importance of the home in this connection. As the National Manpower Council recently pointed out, "It is not possible to acquire skill, and surely not possible to acquire a high level of skill unless one is motivated to do so and puts forth real effort." Few become skilled workers by accident. Although relatively little is known about the growth, during the formative years, of basic values, connected.with work, there can be no question that the child develops these values largely as a result of his relations to his parent, and other key persons in his environment. If the father hates his work and the mother fails to plan for the future, these considerations will be reflected in the later work attitudes and behavior of their offspring. (29, p. 98)

Ginzberg goes on to cite evidence that almost twice as many Negro mothers than white work full time and the fact that a major portion of young Negroes are brought up in homes which the father has deserted or in other fatherless situations in which continuance of the family unit depends on the mother or relatives.

A chapter in the book Education in the Metropolis (48) deals with the Negro family and utilizes research conducted by Daniel Moynihan which aroused vast national controversy when presented in 1965. Moynihan argues that "massive effort must be directed toward the establishment of a stable Negro family structure" (46, p. 249). He cites a variety of studies to substantiate his views which indicate that Negro males do poorer school work than Negro females from the 
start of school; that more drop out; that a direct relationship exists between intelligence test scores and the presence (or absence) of a father with higher scores when a father is present; that a considerably higher proportion of Negro (than white) youth come from broken homes; and, that even grade level retardation is higher when only one parent is present and highest (for Negroes) when neither parent is present which is again a more frequently found statistic among Negroes than whites. He further cites the loneliness of the Negro child where the need to talk over an education problem is concerned and uses as evidence a 1959 study made in Connecticut of high school drop outs.

Two important factors must be considered in quotations and ideas covered in the preceding references to Ginzberg and Moynihan. These were the necessity for motivation of a sustained and high level if one were to acquire skills and the seeming fact that a family life and an adequate neighborhood environment are a part of that motivation. On both counts the Negro suffers a distinct disadvantage. He often has no family life, comes from an area of bad housing, high crime rate, high rate of unemployment, a family held together by a working mother or by a mother and relatives or by relatives or someone standing in place of a family, and the older boys and girls he knows rate high statistically in the production of school drop outs and constitutes a higher than national average proportion of other indications of social disorder as venereal disease, pregnancy, crimes--both minor and major, drug addiction, and a type of inverted status for those who find a way to dress reasonably well, drive a car, and not work. This is hardly an 
environment which spawns a high level of motivation for school and yet it is the school which must provide the major opportunity for the acquisition of skills and values which will help the Negro escape from the unemployment, non-involvement in typical citizenship, and deeper than average involvement in those factors and activities which tend to disrupt rather than build society.

If the Negro is in the North then he will most likely live in a large city and it is common knowledge that big cities have school buildings that are usually much older and less modern than the bright new suburban areas to which many white citizens have fled. And it is also common knowledge that the neighborhood school concept so prevalent in the North is certain to send the Negro student to a school that is mostly Negro or soon becomes that after he moves into the neighborhood. And it is equally common knowledge that it is this type of school in which it is most difficult to attract what is so urgent1y needed....the best of teachers available to that city.

Wattenberg (76, pp. 291-298) has a vivid picture of the teacher problem in the neighborhood school which is mostly Negro in enrollment. Case studies of teachers revealed that middle-class white teachers were fearful of teaching in such a school. They feared the difficulties of motivating the children, feared the fact that securing adequate achievement would be impossible and might reflect against them, were fearful of discipline problems they were certain would be encountered, and fearful even to enter the neighborhood for night meetings. A11 too often, too, as many other authors have pointed out and as the granting of special 
federal assistance substantiates, the equipment, money per pupil, and materials were either sub-standard or, if equal, not equal enough to do the unequal job required.

A poem by Terrence Johnson seems to aptly sum up what a Negro child all too often finds both in school and in his future.

I view solemnly the cracked walls. They stand cold....1ifeless.

I view garbage overflowing in the streets. It's filthy.....lifeless.

Then I see my child.

He lives between these roach-infested walls

He plays in these filthy streets.

He is full of life, by no means lifeless.

My son brings these crevice-streaked walls, These filth-lined streets to life with just his presence. They seem to laugh at me, reflecting, reflecting, Reflecting greater than any mirror, my failure. My son cannot envision his future. Only I see his destiny.

It hurts to see such a glum picture. (12)

Yet what the Negro child faces as outlined in the above poem is not vastly different from what other groups face and have faced....both individuals and groups. All of the immigrant groups who came to America lived in ghettos and slums; many were discriminated against openly and subtly; others were openly and bitterly unwanted and attempts were made to drive them out. These groups...Italians, Slavic peoples, Orientals, Jews, Catholics, fought back, each in their own way but they built around their own culture and their family life a new texture of stability and strength which enabled them to overcome discrimination, utilize and profit from education, and develop an American citizenship in which they could, if they wished, hide their previous origins. 
Kardiner and Ovesey (35) claim the Negro had a uniquely more difficult position than other minority groups because he, the Negro had an aboriginal culture which was smashed and that no aboriginal culture could have avoided being smashed by the conditions of slavery. They state:

This smashing of culture means, in effect, that the old types of social organization and all their derivatives could not continue, but a new type of emergent adjustment derived from the new conditions would have to be established. This kind of situation has arisen many times in human history. The incentives for such emergent changes in adaptation are usually the inadequacy of the environment in which the groups finds itself. (35)

They also point out that the usual reaction of the group is a voluntary move to make a new start after adaptive possibilities have been exhausted in the old environment. The Negro, however, did not come to America in a voluntary move to better his environment. He was forced, against his will, into a new environment and a new culture but his own culture was destroyed whether by design or by circumstances. His culture then (and it certainly varied within the groups of Negroes who came here against their wills) was imposed from without by slavery and his communication was mostly with others undergoing the same condition.

Many writers have explained the uniqueness of discrimination and of handicaps which plague the Negro, one of the latest being James Baldwin who points out among other things that the Negro cannot hide from the fact that he is a Negro because of the color of his skin whereas other minority groups "cannot be distinguished one from another at a football game" (6), Baldwin and others also point out how black is 
viewed in undesirable ways in our American culture....associated with death and funerals, magic, superstition, and the like. Silberman (65) in an excellent article on the Negro in the city points out how different times were when other immigrants flooded the cities. Then immigrant labor was needed, now it is not. Then the city did more than merely use the newcomers; it equipped them to take their place as fully participating members of the U.S. society.

Silberman sees the city problem as one that concerns mostly the Negro and the facts about why the Negro is not being absorbed into the cultural life of the city. He cites the fact that between 1950 and 1960 the twelve largest cities in the United States lost over two million white residents but gained nearly two million Negro residents. And he claims that the large city while forcing the Negro (as it has past immigrants) into the slums no longer allows the slums to act as "the incubator of a new middle class." He goes on:

One reason for this failure is that city planners have been more interested in upgrading the value of the city's real estate than in upgrading the lives of the human beings who inhabit the real estate. They have tried to create middle-class neighborhoods by driving lower-class Negro residents out of the neighborhood being renewed, and bringing white middle-class residents in; Negroes bitterly refer to urban renewal as "Negro removal." (An estimated 80 per cent of the families relocated by urbanrenewal projects have been Negro). (65)

A11 of the other ideas previously mentioned as descriptive of the unique problems faced by the Negro are mentioned by Silberman (65): twice as many Negro girls as boys going to college (almost a direct reversal of what is the ratio among whites); ease of the Negro to be sighted; the mass feeling of dislike of whites for Negroes that live 
next to them (or rather fear of that if it should happen); the lack of job opportunity for Negro men and the ease of Negro women finding jobs as maids; the large numbers of Negroes engaged in unskilled labor and the widening gap between the education of the Negro and the requirements of the labor market. He speaks also of the disintegrated family life and of the difficulties of escape of the Negro from a ghetto environment and a slum way of living. And he recognizes the plight of the Negro in its many aspects for he says:

It would be a serious mistake to equate the Negro's apparent apathy and lack of motivation with a sense of contentment. It is a lot harder for today's Negro to bear his poverty and lack' of status than it was for European immigrants who arrived at a time when the great majority of the population was poor.... Like the underdeveloped peoples everywhere American Negroes have been fired by the revolution of rising expectations.

Silberman recognizes also that Negro advances will require changes with the Negro as well as the white community. The end of all discrimination (if this came tomorrow) would not solve the Negro problem for "the truth is that too many Negroes are unable.... or unwilling... to compete in an integrated society." And though Silberman does not say it in so many words....this is a time when qualified Negroes can find jobs; a time even for them to be given preference over whites who have had more experience or earn higher qualification scores on whatever system of evaluation is used.

The Negro problem is the urban problem. Several have said it and though other minority problems exist with Mexican Americans, Puerto Ricans, and white rural immigrant hillbillies from the worn out coal 
fields and fading agricultural areas such as Appalachia, when people today speak of the city problem they refer mostly to the Negro problemand no aspect of this problem is more acute than is the portion that concerns education.

Intelligence, the Negro, and Retardation

An article in 1952 on psychological tests and the education system quoted a psychologist named Hieronymus as saying, "the best prediction of how far a child will go and how well he will do in school is the occupation of his father." (62, p. 226) Today Hieronymus might add that this prediction could be made even more valid if the child were black, and either had no identifiable father or did not live with him.

The American Research Association (a part of the National Education Association) published a pamphlet in 1962 on the educable mentally retarded child. This document estimates that from three to four percent of the public school population in the United States living in average or superior socioeconomic communities would have an IQ above 50 but below 75 and from one to two percent (from such favorable communities) would be below 50 in IQ. Where below average socioeconomic communities are concerned, from six to seven percent are below 75 but above 50 in IQ, and from one to two percent are below 50 . Therefore, acceptance of this estimate would mean that from nine to eleven percent of the school population have an IQ between 50 and 75 , and from two to four percent have an IQ below $50(4, \mathrm{pp}, 6-7)$. 
One of the 1967 yearbooks of the National Society for the Study of Education is devoted to the educationally retarded and disadvantaged. It divides them into these three groups:

1. The educationally retarded who are performing below grade level commensurate with age level due to inherent limitation of mental ability;

2. The educationally retarded who are performing below grade level commensurate with age level in situations in which the standards are based on the performance of groups for whom different educational and sociocultural opportunities have been available;

3. The educationally retarded who are performing below grade level commensurate with age level due to lack of interest and motivation. ( 7, p. 99)

One of the fascinating aspects encountered by anyone seeking information relative to racial differences (where the Negro is concerned), is the fact that even objective study of possible racial differences seems to arrouse a wall which is difficult to penetrate. There appears to be either a widespread conviction that racial differences do not exist and thus that study is useless, or that any study of differences is motivated by racism or neo-Nazism or some other undesirable interest.

Stodlosky and Lesser made a recent study of racial differences (which will be analyzed later) that involved Negroes. They said, "perhaps the most formidable problem was that of gaining cooperation of 
school authorities for research on such a supposedly controversial issue. An honest approach by the researcher must contain the words 'ethnic,' 'Negro,' 'Jewish,' and 'Iower-class,' yet it is precisely these loaded words which arouse anxiety and resistance in those who are authorized to permit or reject research in the schools." (68, p. 564).

A recent article in the Journal of Negro Education illustrates the difficulty of accepting reports on research if the topic is controversial. This article analyzes and summarizes a number of studies on the general topic of deprivation and its effects on intelligence, achievement, and cognitive growth. (19, p. 5). The authors say that, in three of four studies involving white and Negro children from northern integrated areas, "no significant differences were found between the races." (op. cit., p. 6) A review of these studies by Shuey (63) which gives much more detail reveals that one of them dealt with the Goodenough Draw-a-Man test, which is no longer considered useful for measuring intelligence (63, p. 12); another compared Negroes with white children who were drawn mostly from homes where English was not spoken (63, pp. 263 and 323 ); and a third dealt with a matched sample of white and Negro persons in an institution undergoing treatment for psychoneurotic illness (63, pp. 202, 214 , and 324).

Audrey Mary Shuey's book (63) which provides this greater detailed information about these studies, is foreworded by $\mathrm{Dr}$. Henry Garret, who sumarizes Shuey's findings as follows:

1. The I.Q.'s of American Negroes are from 15 to 20 points below those of American whites. 
2. Negro overlap of white median I.Q.'s ranges from 10 to 25 per cent. Equality would require 50 per cent.

3. About six times as many whites as Negroes fall in the gifted child category. (in a numerically matched Negro-white sample)

4. Negro-white differences in mean test scores occur in all types of mental tests, but the Negro lag is greatest in tests of an abstract nature; for example, the lag is greatest in problems involving reasoning, deduction, and comprehension--functions called for in education above the lowest levels.

5. About six times as many Negroes as whites fall below 70 I.Q. ...i.e., in the mentally retarded group.

6. Differences between Negro and white children increase with chronological age, the gap being largest in performance at high school and college levels.

7. Large and significant differences in favor of whites appear even when socioeconomic factors have been equated (63, pp. 58-59).

The fall 1967 Issue of the Harvard Educational Review contains a report of studies on the disadvantaged by Stodolsky and Lesser. (68, pp. 546-589). This highly condensed but exhaustive article reports, particularly on a study made by the authors in which they compared the scores of both middle and low socioeconomic groups of Jews, Chinese, Negroes, and Puerto Ricans, on four aspects...verbal ability, reasoning, 
number facility, and space conceptualization. They concluded that ethnic and racial factors do affect the pattern of mental abilities and "once the pattern specific to the ethnic group emerges, social-class variations within the ethnic group do not alter this basic organization" (68, p. 567). This study of New York children (six and seven years of age) revealed that in all instances, however, middle class children scored above lower class children in the same ethnic group. Where the different groups were concerned the results were as follows: VERBAL ABILITY. Jewish first, Negro second, Chinese third, and Puerto Rican last. SPACE CONCEPTUALIZATION. Chinese first, Jewish second, Puerto Rican third, and Negro last. Specific standings on the other two categories were not given, but the combined mental ability scores showed Negroes to be third (above Puerto Ricans) in reasoning, and last in number scores.

This article takes sharp issue with the Equal-footing recommendations of the Coleman study (carried out by a commission established by Congress and the President; published in 1966), which would attempt to develop all groups equally, whereas these authors believe research indicates that racial and ethnic groups do differ and that each should be educated according to his specific strengths.

Is intelligence racial? Do racial and ethnic differences really exist? There seems to be little or no doubt that differences do exist but whether they can be attributed to environment, or race, or both, does not seem clear. One fact stands out.... we need to examine much more carefully (and courageously) than we have in the past possible 
differences in racial and ethnic groups, if we hope to solve existing problems in their educational attainment as equal citizens. 
INTELLIGENCE, COMPENSATORY EDUCATION, AND SCHOOL ACHIEVEMENT

"Compensatory education has been tried and it apparently has failed." This is a direct quotation from a highly controversial article in the Winter 1969 Issue of the Harvard Educational Review by Arthur R. Jensen of the University of California (33, pp. 3-123).

The article of Dr. Jensen's contains a highly unusual and unique attempt to analyze what intelligence actually is by utilizing the hypothesis that intelligence can be measured (he actually admits it is easier to measure than define, an interesting comment) and he deeply involves himself in a difficult attempt to separate what is measured into factors that are genetic in origin and environmental. Anticipating controversy over the article, the editors of Harvard Educational Review Introduced the article as follows:

Arthur Jensen argues that the failure of recent compensatory education efforts to produce lasting effects on children's IQ and achievement suggests that the premises on which these efforts have been based should be reexamined.

He begins by questioning a central notion upon which these and other educational programs have recently been based: that IQ differences are almost entirely a result of environmental differences and the cultural bias of IQ tests. After tracing the history of IQ tests, Jensen carefully defines the concept of IQ pointing out that it appears as a common factor in all tests that have been devised thus far to tap higher mental processes.

Having defined the concept of intelligence and related it to other forms of mental ability, Jensen employs an analysis of variance model to explain how IQ can be separated into genetic and environmental components. He then discusses the concept of "heritability," a statistical tool for assessing the 
degree to which individual differences in a trait like intelligence can be accounted for by genetic factors. He analyzes several lines of evidence which suggest that the heritability of intelligence is quite high (i.e., genetic factors are much more important than environmental factors in producing IQ differences):

After arguing that environmental factors are not nearly as important in determining IQ as are genetic factors, Jensen proceeds to analyze the environmental influences which may be most critical in determining IQ. He concludes that prenatal influences may well contribute the largest environmental influence on IQ. He then discusses evidence which suggests that social class and racial variations in intelligence cannot be accounted for by differences in environment but must be attributed partially to genetic differences.

After he has discussed the influence of the distribution of IQ in a society on its functioning, Jensen examines in detail the results of educational programs for young children, and finds that the changes in IQ produced by these programs are generally small. A basic conclusion of Jensen's discussion of the influence of environment on IQ is that environment acts as a "threshold variable." Extreme environmental deprivation can keep the child from performing up to his genetic potential, but an enriched educational program cannot push the child above that potential.

Finally, Jensen examines other mental abilities that might be capitalized on in an educational program, discussing recent findings on diverse patterns of mental abilities between ethnic groups and his own studies of associative learning abilities that are independent of social class. He concludes that educational attempts to boost IQ have been misdirected and that the educational process should focus on teaching much more specific skills. He argues that this will be accomplished most effectively if educational methods are developed which are based on other mental abilities besides I.Q.

Because of the controversial nature of Dr. Jensen's article, the Spring Issue of the Review will feature a discussion of the article by five psychologists: Carl Bereiter, Lee Cronbach, James Crow, David Elkind, and $\mathrm{J}$. McVicker Hunt. Readers are also invited to react. (30, pp. 1-2) 
Following the above promise the Spring Issue devoted 87 pages covering seven comments by psychologist Car1 Bereiter (Ontario

Institute for Studies in Education), William F. Brazziel (Norfolk State College), Lee J. Cronbach (Stanford), David Elkind (Rochester), J. McV. Hunt (Illinois), Jerome S. Kagan (Harvard) and by geneticist James F. Crow (Wisconsin) as well as a letter from Benjamin S. Bloom (Chicago). A descriptive summary which appears to accurately assess the high points made by the above scholars is found in the June issue of the Bulletin of the Council for Basic Education (18). This summary is as follows:

As might be expected, none of the commentators questions Jensen's first thesis that there are substantial differences in individual intelligence. Most of them, moreover, agree with Jensen that there is a large genetic element in these differences. Bloom, who describes himself as an "unbridled environmentalist," disagrees, as does Brazziel, by implication. Kagan also seems to disagree, contending that mother-child interaction at very early ages is extremely important. When it comes to Jensen's contention that there are marked racial and social class differences in genetic intelligence, almost all the commentators take the position that this is unproved. Brazziel, a Negro, hotly denies it, and implies that Jensen and the Review were irresponsible in providing ammunition for racists. Crow says that "is is foolish to deny the possibility of significant genetic differences between races," but that the evidence is "not at all conclusive." Cryptically, E1kind agrees with Jensen that "it does not pay to blink at the facts" that "have to do with racial or socio-economic differences in intelligence."

Turning to Jensen's premise that all compensatory programs have failed, most of the commentators disagree. Brazziel does so flatly. Bloom says that some have, some have not. Crow says he is unfamiliar with the data, but warns that "we should not give up too easily." Hunt agrees that Head Start has failed, but not all compensatory education. 
He says that overselling of some compensatory programs has led to an "overkill" which may deprive us of valuable opportunities. Cronbach is more pointed: "There has been too much blithe optimism about our ability to improve the intellectual functioning of the slum child and the retarded child. Programs of compensatory education seem to have had no reliable and lasting effect. It may have been a sound political decision to launch massive compensatory programs, if only as a token of public concern. But far more was promised than we know how to deliver, and the hectic effort has drawn energies away from the needed basic, objective research."

As for the practical educational implications of Jensen's article, there is some caustic criticism. Bereiter believes that intelligence will become more and more important in our society, and argues that "Jensen's closing appeal for diversity of aims in education inspires more nostalgia than hope, recalling the nearly vanished era when blacksmith, watchmaker, woodcarver, gardener, and a host of others could attain some measure of distinction on the basis of special abilities little related to general intelligence." Hunt contends that genetic factors do not preclude "a general increase in intelligence," pointing to the marked increase in human height "without benefit of selective breeding or natural selection." Cronbach says he hopes "it is inconceivable that data on heredity--whether of the individual or the group--will persuade us that some children should be taught concepts, some taught rote verbal associations, and some taught how to change tires." We would agree with this statement, and with Kagan's conclusion:

...genetic factors are likely to be most predictive of proficiency in mental talents that are extremely difficult to attain, such as creative genius in mathematics or music, not relatively easy skills. Learning to read, write or add are easy skills, well within the competence of all children who do not have serious brain damage. Therefore, it is erroneous to suggest that genetic differences between human populations could be responsible for failure to master school related tasks. Ninety out of every 100 children, black, yellow, or white, are capable of adequate mastery of the intellectual requirements of our schools. Let us concentrate on the conditions that will allow this latent competence to be actualized with maximal ease. (18, pp. 13-15) 
Whatever the outcome about genetic intelligence, racial intelligence, and compensatory achievement, it seems certain that the debate will continue and may even become more intellectually acceptable as scholars look for reasons within the teaching situation itself for failure and success on the part of different individuals and groups. Dr. Jensen's article offers some clues of significance to this project in the final portions of his article (33). He, Jensen says that many of the basic skills can be learned by various means and "an educational system that puts inordinate emphasis on only one mode or style of learning will obtain meager results from the children who do not fit this pattern" (33, p. 116). He believes that present school methods place an emphasis on general intelligence factors which require that one be average or above average if he is to learn at all and this . accounts for the large numbers of high school students who have failed to learn basic skills which could have been learned had they been taught in a different manner. He closes his article with this significant statement:

If diversity of mental abilities, as of most other human characteristics, is a basic fact of nature, as the evidence indicates, and if the ideal of universal education is to be successfully pursued, it seems a reasonable conclusion that schools and society must provide a range and diversity of educational methods, programs, and goals, and of occupational opportunities, just as wide as the range of human abilities. Accordingly, the Ideal of equality of educational opportunity should not be interpreted as uniformity of facilities, instructional techniques, and educational aims for all children. Diversity rather than uniformity of approaches and aims would seem to be the key to making education rewarding for children of different patterns of ability. The reality of individual differences thus need not mean educational rewards for some children and frustration and defeat for others. (33, p. 117) 
It is diversity in teaching with which this project is primarily concerned; and it is diversity oriented chiefly to the basic skills which most authorities believe even the most cruelly disadvantaged can acquire. This project sought to identify these skills by surveying tests which are widely used in the United States each of which supposed1y bases its items on what is taught in the curriculum of the various school systems.

\section{Tests Used in Various Cities}

The battle over what tests measure and what their results show may continue in the future as in the past but irrespective of criticism and conflicts the use of tests continues. Usually in a national controversy such as those currently raging about use of tests by employers, for admittance to a school or a special program, and the new plan for a national assessment of educational attainments in the public schools (66) the use of tests continues. No recent figures were sought but one source showed that in 1958 a total of 122,700,000 printed standardized tests were used in the nation as compared to 87 million in 1954 (45). If use of tests has matched growth in school enrollment and population then the amount currently being used must be in excess of 150 million. The writer of this paper contacted school authorities in 30 selected cities located in various sections of the United States. Each school district in those cities was asked what tests they were using in the primary grades. A total of twenty-three cities replied and some enclosed copies of tests which had been developed locally. (New York 
City, Philadelphia, and Detroit had developed local standardized tests and mailed copies along with their replies). A list of the thirty cities contacted is found in the Appendix.

The twenty-three cities which did reply included most of the large cities in the nation and all twenty-three used some type or kind of test or tests in the primary grades. Breaking the tests down into categories the replies indicated the following:

General Aptitude tests were used by the following cities in their primary grades: Atlanta, Georgia; Berkeley, California; Chicago, Illinois; Cleveland, Ohio; Columbus, Ohio; Dallas, Texas; Detroit, Michigan; Houston, Texas; Jackson, Mississippi; Kalamazoo, Michigan; Long Beach, California; Milwaukee, Wisconsin; Nashville, Tennessee; Newark, New Jersey; Philadelphia, Pennsylvania; Phoenix, Arizona; Seattle, Washington; St. Louis, Missouri; and St. Paul, Minnesota. Achievement type tests were used in the following cities: Berkeley, California; Boise, Idaho; Cleveland, Ohio; Columbus, Ohio; Dallas, Texas; Detroit, Michigan; Houston, Texas; Jackson, Mississippi; Kalamazoo, Michigan; Long Beach, California; Milwaukee, Wisconsin; Newark, New Jersey; New York City, New York; Palo Alto, California; Philadelphia, Pennsylvania; Phoenix, Arizona; and St. Louis, Missouri. Reading Readiness type tests were used in the following cities: Atlanta, Georgia; Boise, Idaho; Chicago, Illinois; Columbus, Ohio; Dallas, Texas; Detroit, Michigan; Houston, Texas; Indianapolis, Indiana; Jackson, Mississippi; Kalamazoo, Michigan; Long Beach, California; Milwaukee, Wisconsin; Nashville, Tennessee; Newark, New Jersey; New York 
City, New York; Philadelphia, Pennsylvania; Phoenix, Arizona; Seattle, Washington; and St. Paul, Minnesota.

A summary of the above shows that nineteen cities administered a standardized aptitude test in primary grades; a total of seventeen cities used a standardized test to measure achievement; and a total of nineteen cities administered a standardized test to measure reading readiness.

Using information gained from the various cities as to types of tests most used an analysis was made of the three leading achievement tests: Metropolitan, Stanford, and California. Originally it had been hoped that these tests would provide clues and ideas which could be modified or used as a guide for teaching ideas for first grade. In general, however, these achievement tests (and perhaps necessarily so) cover skills and use activities similar to what is found in the teachers', guides. A summary of test items used in the three tests mentioned above is confined to reading and other language arts skills which illustrate and illuminate the point just made about similarity to other material readily available to the teacher. The summary follows:

Metropolitan Achievement Test, Grades 3-4

\section{Word Knowledge}

Four choices. Look carefully at underlined word. What word completes the sentence best.

Examples:
A mat is a
chair rug floor couch
Across means
near from away over 
A sip is a little

Ancient is the same as

Challenge means cup boat fall drink

future royal old useless

battle cup choice defiance

\section{Word Discrimination}

Word that goes best where space is.

Examples:

Be sure to your raincoat.

were wore

wear worn

There is a pretty on mother's hat.

very vent

vein veil

Can you extra help when you need it?

odors object

obtain oblige

\section{$\underline{\text { Reading }}$}

Read story. Read questions. Find best answer.

Examples:

Policemen are our friends. They help us to cross the street. They keep cars moving. Sometimes they scold people, but only when people do something wrong. Everyone should obey policemen.

A. How do policemen help drivers?

They keep cars moving.

They scold people.

They drive cars.

They wear blue suits.

B. In this story, the word obey means to-

run home to Mother

do what you are told

sit up

drive fast 
For a long time scientists have been perfecting techniques for collecting fish and keeping them alive for study. One of the Instruments that have been developed for this purpose is called a "deflator." Fish that are taken from deep parts of the ocean often die if they are brought into shallow water too quickly. Nature has given these fish air-filled sacks which help them live In the depths. When the fish is brought up from the deep water, the sac expands, often protruding through the fish's mouth. Unless the air is let out quickly, the fish may explode. After the deflator lets the air out, the fish can live in shallow water.

34. The best name for this story is--

The Deflator

A Fishy Story

Brave Fisherman

Pop! Goes the Fish!

35. The deflator is used most often with--

fresh-water fish

deep-sea fish

man-eating fish

very large fish

36. The deflator is most helpful to--

fishermen

fish canneries

scientists

Iifeguards

37. It is important that the deflator remove the air from the fish's sac--

explosively quietly

rapidly slowly

38. In this story the word protruding means--

exploding interfering

choking sticking out 
Spelling

Word to be spelled is pronounced. Sentence read with word in it (word stressed when sentence is read). Word repeated.

Examples:

moving We are moving into a new house. moving

Delay He came without delay when called. delay

Cause Speed was the cause of the accident. cause

Language

Part A Read sentence. If underlined word used correctly, make a cross on letter $R$ (for Right), or $W$ (for Wrong).

Examples:

I seen the bird fly out of its nest.

[R] [W]

The pony belongs to Paul and me.

[R] [ [

They have broke our best bat.

[R] [间

He does fairly good at catching the ball. [R] [W]

Father will learn me to drive the car. [R] [W]

\section{Part B}

Sample: his teacher is absent today $[V=$ correct $]$ Isnt your aunts house located on Cherry street 9 Dear cousin Fred 9

Our family has a new cabin at Great lake. We are going there next summer.

Will your $\stackrel{P}{\text { mother let you come to visit me }} \boldsymbol{P}$

$$
P_{\text {your }} \boldsymbol{P}_{\text {cousin }} \boldsymbol{Q}
$$


Stanford Achievement Test, Grades 3-4, Form J.

Test 1, Paragraph Meaning

Find the one word that belongs in each space and underline that word.

Examples:

Mary and John live in a big_ 1

1. tree house farm yard

See them laugh. Something is 2

2. funny red big out

When Mary was ten years o1d, she was given ten cents a week. Her brother Tom," who was twelve, got twenty-five cents a week. Mary asked her father why she could not have as much as Tom. Her father replied, "When you are as old as Tom is now, you may have just as much as he gets now." Two years later, when Mary reached her 14 birthday, her father said, "Now you may have 15 cents a $16 . "$

14. next tenth eleventh twelfth 15. five ten twenty twenty-five 16. day month week year

Wool is clipped from live sheep by a process called shearing. The entire mat of fleece from each animal comes off in one piece. W1th electric clippers one man can 41 from 150 to $200 \quad 42$ a day. After shearing, the 43 is rolled up in bundles and sent to the mill.

41. clip run kill feed

42. pounds lambs pelts sheep

43. skin hid fleece cotton 
Test 2, Word Meaning

Draw line under the one word that makes the sentence true. Examples:

1. Eggs come from cattle hens horses pigs.

16. Mary Smith and John Doe are cousins if they have the same

grandmother mother sister daughter

29. The way a person looks is his appearance burden conduct difficulty

38. A place that raises flowers and shrubs to sell is called a nursery plantation garden ranch

Test 3 , Spelling ( 30 words)

Examples:

1. can I can go. can

6. little The kitten is very little. little

15 think I think it went over the fence. think

24 every Fred drinks milk every morning. every

30 hurry You must hurry because it is late. hurry

California Achievement Tests, Grades 3-4.

Test 1, Section A

Look at the boxes below. I shall read one word in each box. You are to draw a line under it. 
Examples:

\begin{tabular}{|l|c|c|c|}
\hline 1 & 2 & 3 & 4 \\
$\operatorname{dog}$ & THIS & goat & read \\
my & THEN & got & red \\
little & THAT & gun & ride \\
\hline
\end{tabular}

\begin{tabular}{|l|l|l|l|}
\hline 11 & 17 & 18 & 20 \\
like & PROMISE & should & POSTURE \\
hike & PROMOTE & shoulder & POSTER \\
bike & PRODUCE & soldier & PASTURE \\
\hline
\end{tabular}

\section{Test 1, Section B}

Look at the boxes below. See the words with numbers in front of them. You are to draw a line from each of these words to the word on the other side which means the opposite. Examples:

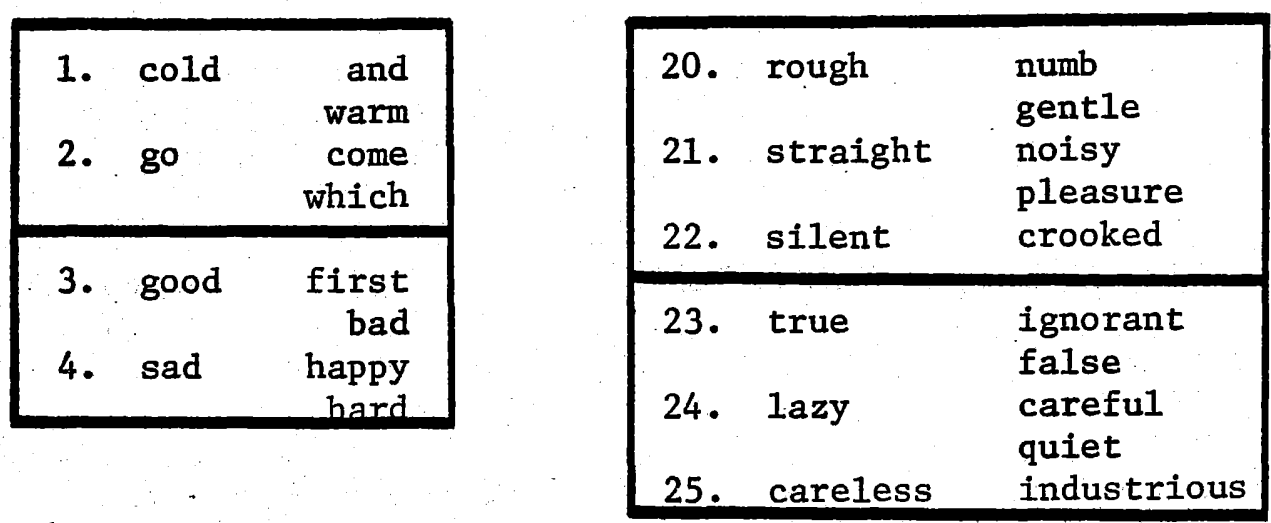

\section{Test 2 , Section 3}

Read each sentence below and do what it says.

Examples:

1. Write this word: boy 
3. Write the missing letter in this word:

d_g dog

9. Cross out a letter to make his out of this word: this

10. Write the number that is two times five on this line:

14. Cross out all the words that end with $\underline{s}$ in sentence number 14 .

\section{Test 2, Section D}

Draw a line under each correct answer.

Examples:

1. The title is found on what part of a book?

beginning middle end

4. The word color is found in what part of the dictionary? beginning middle end

Read this list of words and find the answers to questions

$5,6,7$, and 8 .

$\begin{array}{ll}\text { swing } & \text { stroke } \\ \text { animal } & \text { own } \\ \text { now } & \text { peck } \\ \text { pack } & \text { forest } \\ \text { letter } & \text { Strike }\end{array}$

5. forest would come next after

anima1 peck stroke

8. own would come after

peck swing animal 
Look at the following Table of Contents and find the answers to questions 9,10 , and 11 .

Table of Contents

Chapter

Page

1. A Bird's Nest. . ........ 1

2. The Baby Wrens ....... 7

3. The Robin .......... 15

4... A Mole's Home ......... 31

5. Buzzy, A Little Beaver . . . . 45

9. Draw a line under the number of the page which shows where "Buzzy, A Little Beaver" begins 31 . 45 : 46

11. The story of "The Robin" is found on pages: 15 through $30 \quad 15$ through $31 \quad 31$ through 44

Test 2, Section E

Read each of the stories. Do what it says under each story. Examples:

Jim has a goat.

The goat's name is Billy.

Ne11 has a rabbit.

The rabbit's name is Pinky.

Draw a line under each correct answer.

1. The best name for this story is

"The Toys" "The Pets" "The girls"

2. Jim has a

rabbit goat dog

4. Billy is the name of the

goat boy rabbit 
When grains of corn are planted in the spring, they will grow if they have warm sunshine and rain. Sometimes the farmer irrigates his land if there is not enough rain. The fields must be cultivated during the summer. In the autumn, the corn is ripe and is put in the barn.

Draw a line under the correct answer.

18. To grow, corn must have

warmth and moisture. cold and shade.

a hot, dry climate.

20. To irrigate means

to plant to water to harvest

The following things are told in the story:

Fields must be cultivated.

The corn is put in the barn.

The corn is planted in the spring.

Draw a line under the number that tells the order in which

the above things are told in the story.

23. "Fields must be cultivated" was

1st 2nd 3rd

\section{Word Form}

If two words are the same or mean the same, write $\underline{S}$ on the line between them. If they mean different things, write $\underline{D}$.

1. Can ....................

10. chair................... chain

14. protection..........prediction

25. propeller...........propeller 
Although several of the school districts surveyed had listed readiness tests as part of their primary education testing program, no specific analysis was made of any of the readiness tests. That readiness to learn is a factor of significance cannot be denied but beyond general agreement as to its need and importance, the concept is a matter of controversy not included in this project. Rather the belief that has been followed is that stated by Pestalozzi (25, p. 1081),

All instruction of man is then only the Art of helping Nature to develop in her own way; and this Art rests essentially on the relation and harmony between the impressions received by the child and the exact degree of his developed powers. It is also necessary in the impressions that are brought to the child by instruction that there should be a sequence, so that beginning and progress should keep pace with the beginning and progress of the powers to be developed in the child.

Early in the development of this project an excellent article dealing with learning patterns of the disadvantaged (68) mentioned use of a new test for first grade. A copy of this test was ordered from the publisher and found to be one of the most unique and valuable pieces of material that could be found for this project. Because the test is unique and deals with a new attempt to measure aptitude as well as other aspects of a "first-grader's" intellectual development it was deemed worthy of special and detailed analysis. In as much as the project eventually was aimed at the development of unique and unusual ways to develop basic skills and motivate learning in general areas of first grade activities, the analysis of this test is included in the final portion of the project which does describe what are, hopefully, some unique and creative ideas for teaching first grade. 


\section{CHAPTER IV}

\section{CONCLUDING ACTIVITIES AND SUMMARY}

\section{Applying Testing Ideas to First Graders}

Talking with other teachers and gaining ideas from professional courses often leads one to conclude that nothing is really new in education. As one professor expressed it (and he had been given the idea by one of his professors), education is like a merry-go-round. If you have a special horse you wish to ride and you miss him, don't run after it; just stand still and he will be back. Whether this is true or not, it is apparent that one may engage in a project, or develop some "new" teaching ideas only to find that someone else did it before and may even have done it better.

This project set out to explore testing in general and a particular controversy in testing for depth of knowledge with the purpose in mind of discovering ideas for teaching first grade students in unique ways but in ways that would be acceptable and useful. What had been originally planned was to develop a set of organized ideas which might loosely be called a test in an effort to find out what children in general could learn, how individual children learned, and In what special areas of learning these children might vary due to environment, general aptitude, attitude, experiences, and even genetic influences. Before this could be attempted, however, an article being used as a reference (68) described a project being carried out in New York City which mentioned a test developed for use in this project. This test, titled: From Theory to the Classroom; Let's Look at First 
Graders (42) was ordered and when examined it was so much like this project that one was moved to abandon hours of work and planning, or find a way to use what was contained as something better than you, as an individual, could devise; adding to it only as you found a contribution could be made. (The second course of action was followed and this excellent and unique material was fully utilized).

The reader who has followed the pages that preceded this chapter will recognize that there is a vast similarity between what this project proposed doing and had done with what New York City had proposed and carried out. The previous chapter, for example, used a quotation from Pestalozzi as a guiding principle, and through actual correspondence and analysis the writer had found that standardized tests were not sources one could count on either as ideas for unique teaching or for the accurate measurement of what and how a child from diverse backgrounds could and did learn. With these ideas in mind one can then examine the ideas found in the New York City project and see the similarity. Although it is not mentioned in the test materials nor in any of the booklets describing the project, this unusual test material (42) was even used as a basis for examining possible racial differences in intelligence (68).

An introduction to the project in New York City outlines the following objectives:

1. To develop materials that will help teachers better understand the intellectual development of young children and techniques that will aid them in making systematic observations of important behavioral signs of the child's developmental level. 
2. To develop educational materials, lesson plans, and special tasks that will give children an opportunity to demonstrate certain skills, and, in many instances will provide them with the kind of experience needed to develop their understanding.

3. To develop a series of written exercises that will give the teacher information on a number of aspects of the child's learning abilities. An important feature of these exercises is that they are designed to give the child extensive practice before a measurement for record is made. (42, p. 5)

Some of the references used in this thesis directed attention to the need for diversity in teaching approaches (33) and the acceptance of this need by scholars who disagreed on the relative effect of genetic versus environmental factors but on intelligence agreed that all children could learn if taught in different ways (18). The following quotation seems to bear out the New York project's awareness of a need for diversity and a desire to do something about it:

Those who are interested in the whole critical process of understanding a young child's mental development may find some fresh approaches described here. Those who wonder about the capacities of our school people to cope with the bewildering assortment of backgrounds our pupils represent may find some reasons for confidence. (42, p. 5)

The quotations that follow also bear out the same or similar ideas as those followed and explored in this project. The similarity between the idea found in this reference material from New York City and what has been written in this thesis are readily apparent. As such it summarizes in a sophisticated and scholarly manner what has been written about in this project.

Realizing that skilled and professional assistance from test makers would be needed, the New York City Schools enlisted the services 
of the Educational Testing Service and confronted them with this

question:

How can New York City help its teachers better understand and assess the intellectual development of every entering school child, so that they may teach every child more effectively? (42, p. 7)

The reply for Educational Testing Service made by Henry Chauncey,

their president was:

From Socrates...to Dewey...to Mrs. Thomas in the Bronx and Mrs. Coleman in Brooklyn, educators have eternally struggled with the problem of finding out where young minds are, in order to meet them there. The problem is not a new one.

If the problem is not new, however, the circumstances of its modern setting are. For centuries teachers have answered the challenge of understanding and assessing their pupils by relying on some (often implicit) set of assumptions about human intelligence and some form of testing. From time to time throughout history either the assumptions about intelligence or the forms of testing have changed. Today at least two factors in the contemporary situation suggest that it is again time to revise our ideas and our tools and try to find a fresh approach to the problem.

The first of these factors is simply the reality of modern urban society. The diversity of backgrounds represented in our large cities is now so great that it challenges some of the assumptions involved in the interpretation of present standardized tests. Even more important, however, is the factor of new information and understanding gained during the last two decades concerning the development of the child. While education and psychology are a long way from having all the answers, there is clearly a growing body of knowledge regarding human intelligence: what processes are involved, how these are nurtured, and how they develop. This new knowledge casts grave doubts on many conceptions about intelligence that have permeated our thinking for the last 100 years. What the contemporary context calls for, then, are new approaches to assessment and instruction in terms of our contemporary understanding. It was 
in an effort to find these new approaches that Educational Testing Service and the New York City Board of Education officially joined forces in a cooperative project. $(42, \mathrm{p} .7)$

New York City followed this statement by an outline of why a

fresh approach was needed and all of the quotes that follow are selected because they are summary in nature for this project and highly pertinent for any teacher who deals with or plans to deal with first grade students.

From...ancient Chinese practices to the standardized multiple-choice examinations of present day America, testing has always been a method for estimating the extent to which a person has developed a specific type of knowledge or skill. In the mass testing practices of today, however, there is a tendency to lose sight of this one essential function of the test. $(42, \mathrm{p} .9)$

Today standardized tests are used extensively throughout the country for a variety of educational purposes. There is little doubt that the specialized science and technology of measurement have provided the schools with better and more useful tests. But like all earmarks of progress, this particular specialization has its drawback--it has meant the separation of test maker and test user. In the case of tests used to assess learning ability this separation of test and teacher has often resulted in a confusion of the underlying test assumptions with assumptions about the nature of intelligence. Specifically, there is a rather widely accepted idea that intelligence means a person's inherited potential and that an ability test or intelligence test measures this potential....the confusion of this idea with the underlying assumptions of standardized tests constitutes, in and of itself, one limitation to the continued use of these tests. (42, p. 9)

The assumption of equal exposure to a school environment must hold reasonably well, or the score will not accurately reflect the student's demonstrated ability to benefit from past school experience.

It is evident, however, that aptitude tests which assume the development of certain skills based on past 
school learning are inappropriate for use in the early elementary grades. Such tests are more appropriately administered only after the child has had a sufficient exposure to the school's instruction. In practice, this has usually meant that scholastic aptitude tests are not administered below grade 4 . (42, p. 10)

Certain ability tests are commonly administered below grade 4, however, and these make a slightly different assumption. This assumption--inherent in most general IQ tests--is simply that on the whole, children have had very similar environmental experiences. If this is true, one might test for certain skills children presumably should have learned from their general exposure to life, compare them on the basis of test results, and make the same kind of inference as the aptitude test. Needless to say, this assumption of similar environmental experiences is clearly inappropriate when applied to children in large urban areas who come from a wide diversity of backgrounds. In this way, then, modern urban society poses some problems for current ability tests used at the early grade levels. (42, p. 11)

What currently available tests do not tell the teacher is how children learn, how their intellect develops, where they are with respect to some scale of development, or what the teacher may do to foster development one notch further along the scale. To do this, tests would have to be based more on a theoretical understanding of how abilities develop than they are at present. (42, p. 11)

Thus, for the job of assessing the intellectual development of young children in the New York City schools, sole reliance on current ability tests seems an inadequate approach. What should be sought is the compilation of the best available theory and evidence we now have and the translation of that information into practical, helpful tools for the teacher. As we come nearer to achieving this goal, it will become increasingly difficult to distinguish between the functions of teaching and testing. They will blend imperceptibly into each other. (42, p. 11)

Four basic assumptions upon which the New York City project 
1. Intelligence is essentially a set of developed skills rather than an inherited characteristic.

2. Intellectual skills develop as a result of the child's continuous interaction with his environment.

3. Children are inherently motivated to explore and master their environment.

4. Intellect develops through a sequence of related stages that produce qualitative change in the way children think and are able to deal with the world. (42, p. 12)

The actual test and material developed as a guide for first grade teachers in New York City were organized in six broad areas. The sixth area ("General Signs of Development") requires observational skills on the part of the individuai teacher and were not used in this project. The eventual purpose of this project, however, was to develop unique and unusual ideas for teaching first graders in an effort to develop their basic skills and help them assess and discover their own abilities. The lessons which follow have been gleaned from such a wide variety of sources and persons that it would not be possible to document their original authors. Lessons from the New York City project are included because they were exactly what was sought: unique and unusual ways to engage children in learning activities and the lessons and ideas utilized in this project follow the same pattern of organization as used in the New York Guide, (with the exception of area six mentioned above). These major areas are as follows:

Major Area

1. Basic Language Skills
Developmental Concept

Auditory Discrimination and Attention

Listening Comprehension Learning to Communicate Language for Thinking 
2. Concepts of Space and Time

3. Beginning Logical Concepts

4. Beginning Mathematical Concepts.

5. The Growth of Reasoning Skills
Learning Shapes and Forms

Spatial Perspective

The Notion of Time

Logical Classification Concepts of Relationship

The Conservation of Quantity One-to-One Correspondence Number Relations

Understanding Cause and Effect Reasoning by Association Reasoning by Inference $(42, \mathrm{p} \cdot 21)$

\section{Basic Language Skills}

A. Auditory Discrimination ["...the ability to distinguish changes in the volume, pitch, or rhythm of sound and the ways these changes take place (42)], and Auditory Attention "...the ability to direct and sustain attention to sounds. If the child lacks either skill, he will have difficulty with comprehension" (42) .

1. Behavior Illustrations

a. Child identifies various sound effects accurately.

b. Child repeats foreign words or nonsense words correctly.

c. Child identifies or supplies words that rhyme with another word.

d. Child can tell about the sounds he hears in a short period of time with his eyes closed (42).

2. Instructional Suggestions

a. A "Secret Sound Room" is set up in the classroom (using a portable screen, a large box, etc.) from which teacher and/or students can create sound effects for other students to identify. As students guess, teacher can list responses on the board, perhaps also asking students why they think a certain object and/or action is eliciting the sound. Students may give such responses as: "It sounded whirry;" "It sounded buzzy." Teacher then can list descriptive words given under each guess, thus reinforcing an individual child's thinking through his response, stimulating development of broader vocabulary for the group as a whole, and conditioning children to connect language to the printed word. 
b. Rhyming game: samples: You say "box,"

$$
\begin{aligned}
& \text { I say "animal," } \\
& \text { You say "fox." } \\
& \text { You say "bean," } \\
& \text { I say "gir1," } \\
& \text { You say "Jean." }
\end{aligned}
$$

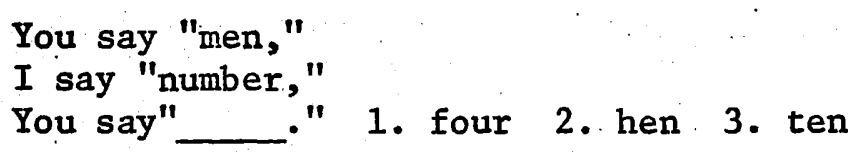

This game can be used on a completely verbal basis with a child or a group; the chalkboard can also be used to present a rhyme like the last example, with some choices given (perhaps provided by a child or group). Children and/or teacher can write some similar "mystery poems" on cards which can be deposited in a "poem bank" for other students to solve. Word recognition tools which can thus be reinforced out of a listening activity such as this could be referred to as "detective clues."

c. Long and short vowel listening game: Children close eyes; teacher or student then says a word that contains a long or short vowel (e.g., "ant;" "blast;" "cheek"). If the vowel is 1ong, children raise their hands; if the vowel is short, children only hold up a finger.

d. Whispering game: A timer is set; teacher then whispers a nonsense word or phrase to one child, who passes on the message to his neighbor. The message continues to be passed until the timer rings. The last child to have been given the "secret message" tells what he heard.

e. "Silence Game:" Children close their eyes and listen for the teacher to whisper one child's name. When that child hears his name, he then becomes the one to whisper another child's name--or the teacher may then whisper another name.

f. Listening game: Teacher tells class she is thinking of one child's name, or a group of children's names. The clue she will give about whose name(s) she is thinking of, will be a word that rhymes with the name(s); (other clues which could be used: a word that starts with the same letter; a word that ends with the same letter; a word that is made up of the same number of letters, etc.) 
g. Individual children or the class as a whole including the teacher can collect pictures that interest them. Student(s) can then focus on different pictures simultaneously as a class exercise, or on an individual basis with the teacher, to find as many items as possible that begin with the same letter. Pictures could be compiled in a book, leaving space for names of items in the pictures that begin with specific consonants to be listed.

h. Listening Game: "What Am I?"

Example: I am the first sound and last sound in did.

I am found in mend, red, and wanted.

I am at the end of find.

I am found in bird, down, and sled. What am I?

i. Listening Game: If all the words I say begin with the same sound, fold your hands; if a certain word does not begin with the same sound, raise your hand, and tell the word that began differently. (The child who first gives the word that begins differently may then whisper to the teacher the letter he would like the next series of words to focus upon).

j. Game: "Where Is The Sound?" If the sound being "searched for by ears" is in the beginning of the word given, children place palms on left side of desk; if the sound is at the end of the given word, children place palms on the right side; if the sound is in the middle of the word, palms are placed on the center of the desk.

k. Who Will Get His Sack Lunch:" All the people that have something in their lunch that starts with the letter p, like in pig; now, all the people who have something in their lunch today that begins with the letter 프, like in much."

1. "Dog and the Bone:" the "dog" (selected by teacher) sits in front of the room, his back to the class, his "bones". (a basket of letters, words, etc.) under his chair. A volunteer sneaks up behind the dog and snatches a bone, then returns quietly to his seat. The "bone snatcher" gives two barks from his seat as a sound clue as to who the culprit is. The dog then turns to face the class, and has three chances to guess who took his bone. If he guesses correctly he may remain the dog; if he cannot guess who it is, the "culprit" gets to take his place, if he can tell and show the class the name of the bone he took (i.e., the letter or word on the "bone"). 


\section{B. Listening Comprehension}

1. Behavior Illustrations

a. Child follows directions given by the teacher or by another child (e.g., follows directions in games such as "Simon Says").

b. Child is able to get the meaning of words from context or from gesture and tone of voice of the speaker.

c. Child retells a story, getting across the "big ideas," the moral, by speaking, drawing, or dramatizing.

d. Child responds to comments or questions directed at other children-- a withdrawn child may do this and yet not respond to questions directed to him.

e. Child laughs at the right time when a story is read, showing that he understands what is funny (42).

2. Instructional Suggestions

a. Guessing game: read a short paragraph and ask for a missing word which can be determined through use of context clues.

Example:

Butch is a clean and cautious eater. He dunks everything he eats into a container of water. He sneaks into the yard to munch on tidbits at night. A stranger might mistake him for a little burglar; the fact is he looks like a masked bandit, especially in moonlight, as all do. (racoons)

Added practice at listening could be integrated into a game such as this by having some students listen as we11 for words beginning with certain initial consonants, words containing certain blends, etc. These students then might report their words to the rest of the class; teacher or a student could write the words mentioned on the board to help reinforce reading skills.

b. Listening game: Say to the class, "Think of a word that rhymes with the last word I say." Youngsters who readily comprehend the meaning of the directions will respond with "day," "may," "clay," etc. Later, as students gain proficiency in playing the game, and as the teacher sees that the majority of the students are prepared to play a more involved version of this listening-comprehension exercise, the game may become one in which students are to "think of a sentence that begins with a word that rhymes with the last word I say." (e.g., "May I use any rhymes?" followed up by some other student with, "Times have changed since I was a baby," etc.) Sentences should make good sense and fit together or at least make good nonsense. 
c. Listening-comprehension-action game: Children must listen carefully in order to follow the action described. For example, "George Giraffe was walking (children walk in place) in the hot grassland one day. He looked all around for food (children shade eyes and look about them). He stretched his long, long neck straight up to reach some tasty leaves. He munched nine leaves." Immediate feedback is provided in this "game" for the teacher in respect to where certain children are in development of listeningcomprehension.

d. Children pantomime what is implied by different phrases supplied by the teacher. Focus on listeningcomprehension abilities of individual children by changing the implications of the series of phrases supplied only slightly, such as:

"Here is my pet in the box."

"Here is my pen on the box."

The sentences used can later be listed on the board and compared in respect to how much just one or two letters (sounds) can change what we mean, both in written and spoken language.

e. Occasionally, the teacher could discuss, then post in written form, some "silly seatwork" directions, such as:

1. Work row one of your arithmetic problems.

2. Sit under your desk; count quietly to 15 .

3. Finish row two of your arithmetic problems.

4. Stand up, walk quietly to the door, then go slowly and quietly around the whole room once. Then go back to your desk.

5. Finish row three of your arithmetic.

6. Walk silently over to the window and count the number of swings on the playground. Go back to your own seat, and draw a picture of a set of anything you want that has the same number of things in it as the set of swings.

\section{Learning To Communicate}

1. Behavior Illustrations

a. Child uses gestures or other nonverbal means to make himself understood.

b. Child translates or interprets information to another child, to his parents from school, or to the school from his parents.

c. Child uses words with common meaning and speaks in reasonably complete sentences.

d. Child tries to justify his own reasoning or persuade other children to see his viewpoint. 
2. Instructional Suggestions

a. Guessing Game: "Who Am I?" One child selected by the teacher, whispers to the teacher "who he is," then goes to the front of the class and gives the class some clues about who he is. For example:

"I am very big.

I have a long nose.

I am an anima1."

First child to accurately guess who he is may be "it" next. This exercise calls upon children's abilities to describe things, and helps reinforce development of understanding and use of language for effective communication.

b. Discussion of simple sentences: teacher and/or children may have collected an assortment of items which are placed on a desk. Different children may pick up an item which especially interests them and verbalize a complete sentence about that object. Sentences could be taped, typed up by teacher onto slips of paper which students could then "proofread" and write over into a booklet, including an illustration of the item each child discussed.

c. Packets of sequence cards can be constructed by the teacher for individual students to manipulate. Cards could have pictures mounted upon them portraying a series of phases of an activity, or each card could have a simple sentence printed on it, the series of cards, when placed in correct sequence, telling a short story.

d. Teacher can mimeograph some "scrambled sentences" which can be cut apart from one another into strips. Individual children can then pick a "scrambled sentence" of their choice, cut apart the words, assemble them into meaningful order, have the teacher or another child read and check over their sentence, then paste the words in correct order on a sheet of paper and make an illustration to match the sentence.

e. Give different small groups each a vocabulary word to dramatize. Before each group's presentation, their word is written on the board and pronounced. The group then dramatizes about three short scenes, one dramatization exhibiting a correct application of the word involved. (e.g., if the vocabulary word was "cautious," children might dramatize through: 1) rushing out into a make-believe street;2) inviting a salesman at the door into the house to 
wait for mother; 3) asking the opinion of someone respected before spending all your savings on a new bicycle). Discussion would then follow about what the class thought the group was trying to show through pantomime each time, which dramatization depicted the meaning of "cautious," and why.

f. Teacher or students construct a "feeling box" in which can be placed a secret item. A corresponding "clue chart" can be made into which can be slipped a series of descriptive antonyms (e.g., soft--hard; has corners--has no corners). One child may select the secret item behind a screen and insert it into the box; another child may be the "feeler;" and another child may be in charge of the "clue chart," pulling out antonyms as dismissed by class questions directed to the "feeler" about the items he is examining with his hands in the box. After the series of antonyms has been covered, one of each pair of antonyms being left up on the chart for the whole class to see, the class makes guesses as to what is in the box. The first person to correctly determine what the item is gets to insert the next secret item behind the screen.

\section{Language for Thinking}

1. Behavior Illustrations

a. Child understands and is not confused by the fact that a single word can mean different things.

b. Child understands synonyms and can use different words to mean the same object or action without. getting confused.

c. Child understands that some words (and expressions) have a sense beyond their literal meaning (e.g., "Her eyes are glued to the book").

d. Child understands and can use the word "not" in making logical distinctions (e.g., "This goes on the shelf, not on the desk").

e. Child understands logical distinctions made by conjunctions (e.g., "Bring me the paper and the paste;" "bring me the paper or the paste").

f. Child shows increasing use of logical causal connectives rather than a continual repetition of "and" or "and then" (e.g., because, so that).

g. Child understands and correctly uses prepositions (e.g., to, for, under, above, on, in).

h. Child understands and correctly uses comparative words (e.g., small, smaller, large, larger, more, less) (42). 
2. Instructional Suggestions

a. Game; "Te11 About:" after an individual, a small group, or the whole class has read a book, characters' names and other words which have special meaning in respect to the book involved, are exposed, through use of flash cards. The first child to read the word correctly then gets a "bonus" first chance at the next word that comes up, if he can tell something about the character or the word.

b. Teacher directs a statement to the class, and then repeats a word in the statement which is to be replaced by a synonym. (Class can be divided into teams to spark participation, each group containing a superior achiever, an average achiever, and a slow achiever. Teams composed in this manner can be rotated to help build a flexible competitive atmosphere; this type of team distribution stimulates new appreciations of teammates' strengths, and provides slow achievers many times with better incentive to compete and achieve). The first team member to repeat the same statement, substituting the appropriate word with a synonym, earns a point for his team.

c. "Substitute Word Game:" At the beginning of the day the teacher announces she will give some common object in the room a new name--and that everyone (including herself) must remember to call the object by its new name all day 1ong. A pencil may thus become a "curp" for the day. Anyone who forgets to cal1 the object by its new name gets a "mistake point;" children with the fewest mistakes at the end of the day are the winners. This game not only adds incentive for auditory attention, but it also provides children with a concrete experience of the arbitrary nature of language.

d. Illustrated Workbooks: children can draw illustrations of both the literal and figurative meanings of expressions such as "she was beside herself;" the expression can be written under the illustrations. This same illustrated workbook technique can be used in respect to antonyms, synonyms, and words that have many meanings (e.g., "run"...one can have a "run for life," a "run for office," a "cattle run," a "run in her hose," etc.) Several other instructional possibilities can be found under the Behavior Illustrations listed above. 
II. Concepts of Space and Time

\section{A. Learning Shapes and Forms}

1. Behavior Illustrations

a. Child draws various shapes distinctly in pictures.

b. Child makes simple geometric designs or patterns in drawing.

c. Child names the shapes of various objects (e.g., "My toast is a square," "the top of my pencil is a circle") (42).

2. Instructional Suggestions

a. Finding shapes in letters; guessing game: "Part of me is a circle. I start the word 'bounce.' Who am I?"

b. When children are to form a large circle for a game or activity, tell the children beforehand to "find something round in this room." (Then get reports from the children about some of the round objects which they have found). "Now we are going to make a large circle together. See if you can keep the circle we make as round as the thing which you found in the room."

c. Relate basic shapes to concrete, everyday objects-traffic signs, food, etc. Invite research by asking the children to find as many triangular things as they can at home and to and from school, to report about when they get to school the next morning. Illustrated booklets could be made by individuals or groups, in which objects could be drawn, labelled, and categorized according to general shape.

d. Circles Game: each student is given a mimeographed sheet upon which is scattered a number of circles. Pupils can work individually or as teams to see how many different items they can construct from the circles. Students can label their objects, and/or choose a favorite object which they made to write about. Sheets can be compiled into a class book for the classroom or school library. (This activity provides feedback in respect to where certain children are in conceptualizing parts in relation to wholes, and provides reinforcement for student conceptualization of the same).

e. Individuals or teams (competitively, within a time limit, if desired) construct as many named common objects as they can, using one, two, or more shapes. Work can be displayed on a bulletin board and later compiled into a book for maximum reinforcement. 


\section{B. Spatial Perspective}

1. Behavior Illustrations

a. Child draws pictures proportionately in two dimensions (e.g., he draws a man that is shorter than the house).

b. Child draws pictures with some depth representation (e.g., objects in the background do not overlap objects in the foreground; objects in the background are proportionally smaller than objects in the foreground).

c. Child solves concrete spatial problems (e.g., he figures out how to maneuver a wide object through a narrow doorway).

d. Child can correctly identify the left and right of someone opposite him (42).

2. Instructional Suggestions

a. "Maze Games:" provide practice in visualizing space and planning maneuvers through space--both important skills that replace simple "trial and error" methods in logical reasoning.

b. "Where Am I? Who Am I?": guessing game--"I begin with b. I am near Linda. I am far away from Don. Who am I?"

c. Related science experiment: experimenting with a class pet to determine if he is right or left pawed (or clawed).

d. Discussion of familiar things that "fit" (shoes, clothes, putting things in boxes, etc.) "Will this book fit in this box? Will the sun fit in this room? Why? Why not?"

e. Class activity: Have one child stand at the front of the classroom with one side toward the class. "What part of his face do we see from our desks?"

f. Ask children to bring in pictures to illustrate "toward" and "away from." Pictures can be used as short story starters in which directional terms are used.

g. Discuss "along," "across," "with," "against;" 1ist the four words across the chalkboard and have the class contribute examples of activities that involve these movements. Individual children could then make drawings illustrating each of the words, and label them. Same technique can be used with "under," "above," "into," "out of," "through," etc. 
h. Teacher selects a volunteer "pilot" to guide a blindfolded child through the room through use of the directional terms "left" and "right."

i. Discussion of north, south, east and west: "Why do we have words such as 'north,' 'south,' 'east' and 'west' in our language? Who uses them? How can these directions help the weatherman? the driver of a car? the captain of a ship? When could a compass help you? Which way is north from our classroom? South? East? West?" (These directional terms could be posted on the classroom walls).

\section{The Notion of Time}

1. Behavior Illustrations

a. Child is aware of longer and shorter periods of time (e.g., he understands that he must "work faster" to get something done in less time).

b. Child draws a simple sequence of events in pictures.

c. Child is aware of the time sequence of events (e.g., he anticipates a coming event or gets materials ready and prepared before an activity starts).

d. Child shows a developing sense of time duration (e.g., after putting his head down for a given period of time, he can make a fairly accurate guess of how long this has been) (42).

2. Instructional Suggestions

a. Discussion of the relationship between height and age; contrasting the size of a young horse to that of an old tortoise, etc.

b. Discussion of short-term events that can only progress in one direction (the melting of an ice cream cone, the eating of an apple) to reinforce understanding of the most basic element of time--that events occur in time and that the sequence in which they occur is an important factor of the event. Children could choose an event and make their own packet of sequence cards, writing appropriate labels or sentences on the cards.

c. Use a timer in relation to as many classroom activities as possible (e.g., "Let's set our timer for twenty minutes; when the timer rings, the hour hand will look like this and the minute hand like this (demonstrate with an artificial clock face), and it will be time for lunch"). 
d. Clock Guessing Game: This game is played by rows. A home made clock consisting of animal pictures in place of numbers is used. A time is mentioned, such as, "It is now five o'clock." The first child in one row must give the sound made by the animal in the place of five. If he cannot, the first child in the next row gets a chance. The row with the most members having succeeded in making the appropriate animal sounds, wins.

e. Children can keep a time record of blocks of time (e.g., 8:00 to 9:00) for one day spent at home. Time records could be brought back to school, put in booklet form, and shared by students.

\section{Beginning Logical Concepts}

\section{A. Logical Classifications}

1. Behavior Illustrations

a. Child has the ability to match, sort, or relate things on the basis of identical perceptual

gualities (e.g., he knows objects of the same size, color, or shape go together).

b. Child has the ability to match, sort, or relate things on the basis of their functional properties (e.g., he knows that a hammer, nails, and board go together).

c. Child has the ability to match, sort, or relate things on the basis of their similar qualities (e.g., he sees that an apple, ball, and balloon are all round).

d. Child includes or counts himself in the total pool of brothers and sisters in the family.

e. Child defines words in terms of their use or function (e.g., "The U. N. is something that keeps people from fighting").

f. Child breaks down a general class into its various subcalsses (e.g., "Animals are made up of pet animals, farm animals, and wild animals") (42).

2.. Instructional Suggestions

a. Beginning of the school year activity: elicit and list on the board responses from children concerning

"what is alike about us." (age, teacher, room, neighborhood, like to play, wear shoes, have hair, etc.) Each response applicable to the whole class could be listed on a separate large sheet or chart; children could contribute illustrations and sheets could be compiled into a book about "How We Are Alike." Same technique could be used with topics such as animals that swim, animals that walk with four feet, tools used to help build things, things 
that have wheels, things that have a triangular shape about them, things we could use to get a drink of water, etc.

b. Guessing game; "Who Could I Be?": "You use me to ." (e.g.,, "You use me to write;" teacher can list responses on the board as they are given... pencil, pen, chalk, and so on). Evaluate list of responses with children in respect to whether all things listed fit into the appropriate category. Children could perhaps compete as teams when contributing responses. Same technique can easily be applied to topics such as "What are all the red things you can eat?" (two classifications being involved here--redness and edibleness); "What are all the things you could use a candle for?"

c. Class activity: "What is the same about all these words?" (similarity could be initial consonant, number of letters, containment of the same blend, being all names for animals, all "action" words, rhyming words, etc.)

d. Creative writing idea: "What Can I Do With My Nose?" (wiggle, smell, sprout freckles); technique can be applied to any item or part of the body that children can associate various uses for based upon past experience.

\section{B. Concepts of Relationship}

1. Behavior Illustrations

a. Child orders a set of objects along a particular dimension, such as size, height, weight, color, or pitch (e.g., he orders a set of equal-size objects by weight).

b. Child learns to match or relate two sets of ordered objects (e.g., he matches things that are ordered along separate dimensions--the lightest shade of paint for the shortest child).

c. Child understands that each child standing in line (except the first and 1ast) is simultaneously to the right of one person and to the left of another, or in front of one person and behind another.

d. Child understands he is a brother or sister to his own siblings (42).

2. Instructional Suggestions

a. Have children select from a list all of the words that are names of animals and that rhyme; teams could be used in this activity, the team having found the most words that fit both categories being the winning team. 
b. Have children classify all room members in respect to two categories -- hair color and sex, for example. Classification such as this will result in various sets of students. Children could make individual booklets, placing one set on each page, labelling the sets giving the names of the children drawn within each set, and the total number of children within each set.

c. Dictionary readiness: ordering a set of names along the dimension of the alphabet. "Whose first name would come first in the alphabet? Would David's name come before or after Carla's? Why? Whose name would come first -- Sharon's or Shirley's? Why?" For practice in relating two sets of criteria, using the alphabet as one order, children could group the class into sets of alphabetized boys, alphabetized girls, alphabetized redheads, etc.

d. Understanding measurement: "What could we most easily use to measure how wide this piece of writing paper is? What could we most easily use to measure how far across it is from one end of the playground to the other end? What could we best use to measure how heavy this stamp is? how heavy this book is? how heavy this table is?"

\section{Beginning Mathematical Concepts}

\section{A. The Conservation of Quantity}

1. Behavior Illustrations

a. Child understands that an apple or sandwich divided into parts is still the same amount to eat as the whole.

b. Child understands that equal amounts of liquid, when poured into different-shaped containers, are still equal.

c. Child understands that equal sheets of paper, when folded into different shapes, are still equal.

d. Child understands that equal amounts of clay, when molded into different shapes, are still equal.

e. Child understands that a given amount of material, such as a yard of cloth, is still the same whether it is rolled up or stretched out (42).

\section{Instructional Suggestions}

a. An "Experiment Center" can be set up in one corner of the classroom, preferably near a sink), where children can be guided into experimenting on their 
own with such materials as: paper, which can be crushed, folded, torn apart, etc.--using equal sheets for each process; different shapes of containers into which same amounts of liquids can be poured; clay, which can be measured off into equal amounts and then pounded and manipulated into a variety of shapes. Children can discuss results of their experiments with the teacher and/or other students, and then write about and illustrate their experiments.

b. A puppet or other vehicle to focus interest and involvement can be used in a problem-solving approach to matters such as: Is there more or less paper after it has been folded? Will the puppet get as much to eat if his sandwich is cut in two? if his toast is cut in half? Will his jacket get smaller when he folds it up? Will his blanket get shorter if he rolls it up? (students could measure the length of the blanket laid flat with a measuring tape, then measure the edges, corner to corner, of the blanket after it has been rolled up).

c. After providing class with opportunities to experiment with and discuss the concepts of "more" and "less," individual students could each fold a sheet of paper in half, vertically; on the left-hand side of the upper part of the sheet, students could draw an object, and on the right-hand side of the upper portion of the sheet illustrate the same object after it has been cut into pieces, lost a piece, been added to so that it has become "more" than it was before, etc. At the bottom of the sheet students could ask "More, Less, or the Same?" and write about what was done to the object. Individual students' sheets could be compiled into a class book to be shared in the classroom or school library.

\section{B. One-To-One Correspondence}

1. Behavior I1lustrations

a. Child establishes some intended equality by correctly matching objects (e.g., he matches pencils or chalk to children in the room).

b. Child used counting rather than matching to establish numerical equality (e.g., he counts the number of children and then counts out an equal number of paint brushes) (42). 
2. Instructional Suggestions

a. Game; "Word-Math Match:" for pupils in pairs or

teams; make sets of cards out of tagboard such as:

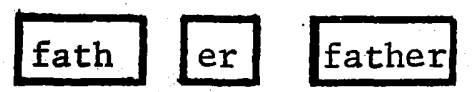

On opposite sides of these cards write the appropriate numerals, which in this particular example would be:

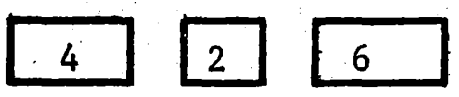

Jumble the sets together; the winner of the game is the person to have matched the most sets within a given time limit, or the first person to have matched a certain number of sets. Each student participating in the game has his own container of the same jumbled sets. (Suggestion: include different words containing the same amount of letters so that students will be required to rely on reading skills as well as ability to match groups of letters along a one-to-one correspondence scheme).

b. Construct a large calendar frame in which students can insert the numbers for the date of each day; at the end of each month, students can clear the calendar, put up the name of the next month above the calendar frame, and sort the pile of numbered cards which are inserted, in numerical order. A technique which can easily be applied to a calendar like this or any calendar, which not only attracts high interest and stimulates children to focus on counting days, and helps foster growth in conception of time, is to insert a printed label of an upcoming event of high interest (field trip, holiday) into its appropriate slot. Students will begin counting "how many days until Christmas," and so on.

c. Attendance chart: each day of the week a different "attendance person" from each row counts the number of people in his row present; each "attendance person" then goes to the attendance chart and inserts the appropriate numerals for his row under columns which proceed from left to right, headed as follows: "Total If All Here," "Number of People Absent," and "Total Here Today!" The above sequence of headings is suggested as it reinforces the subtraction concept.

d. Have students think of all the common objects they can draw with one line, two lines, three lines, four lines, etc.....Students could write sentences under each drawing they make, such as "One line makes a 
flagpole;" "I made this tree out of seven lines," and so on.

e. Spinner game: make a spinner card by attaching an arrow with a brad to a cardboard circle. Draw various diameters across the circle to divide it into parts. Within each part write a numeral or an addition or subtraction problem. In a container collect an assortment of various items (beads, buttons, etc.) The child spins the arrow and selects from the box the number indicated by the numeral or problem upon which the arrow stops. The winner is the child who has the most objects at the end of a given time limit, or who first reaches a certain number of objects.

C. Number Relations

1. Behavior Illustrations

a. Child understands cardinal value (e.g., the number 10 is larger than the number 6 ).

b. Child understands ordinal position (e.g., the fifth day comes after the second day).

c. Child demonstrates his understanding of equal units (e.g., he can make correct change for milk or lunch tickets).

d. Child uses the notion of equal units in measuring things (e.g., "The desk is ten books long") (42).

2. Instructional Suggestions

a. Use of the alphabet for reinforcement of the ordinal aspect of numbers: guessing game; "I am standing in front of the fifth letter of the alphabet. Who am I?" First child to respond with the correct letter, and to say a word which that letter begins, may be the next "mystery person."

b. "What is the largest number that can be written by using the numerals 2 and 4? the numerals 1 and 3 ?" (etc.)

c. An integration of practice at relating numbers, and at reading or listening comprehension: $6+?=10$ is a number story of which one of these written stories: (put the equation on the board)

A1 had 6 bottle caps. He found some bottle caps. A1together he now has 10 caps.
A1 had 6 caps. He got 10 more by trading. How many does he have now? 
d. "King of the Castle:" purpose--practice with combinations. One pupil sits on a chair in the front of the room as the king. The other pupils try to dethrone him by giving him a combination. The king may remain on the throne until he fails to give the correct answer, or until an arbitrary time limit is reached, whereupon the king may select a new successor for his throne. (A game similar to this in format can be used to help reinforce the ordinal aspect of numbers: a list of four or five words which the majority of the class can read is listed beside the king on the board. Children who challenge his throne ask: "Your highness, read the fourth word").

e. "I'm thinking of a number. It is more than 4 , but less than 9. It has four 2's in it. Who can guess?"

f. Game: "What's My Rule?" Teacher asks for a volunteer to say any number "from _ to _.." Then the teacher "secretly" applies the rule (arbitrarily selected by the teacher--addition of 2 , subtraction of 1 , etc.) and responds verbally with the answer only. Children continue to call out numbers to the teacher, one at a time, the teacher responding to each number with a number which is arrived at by applying the rule (rule remaining constant throughout one "game.") When a number of children signal the teacher that they have discovered the rule, the game stops and the rule is discussed.

g. Decorate a box or container of some type that will capture attention. This could be a box with a lid that is notched to become the jaws of a "Math Monster." Inside the "Monster" insert some slips of paper which have on one side a series of three "magic" numbers. Tell the children that each set of three numbers are "magic" because each set is a special family that can do four special things. On the opposite sides of the slips of paper, list the four combinations which can be derived from each set of numbers. For instance:

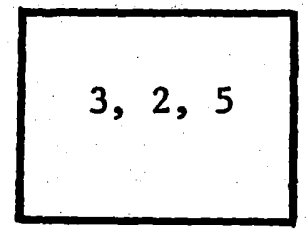

$$
\begin{aligned}
& 3+2=5 \\
& 2+3=5 \\
& 5-3=2 \\
& 5-2 \div 3
\end{aligned}
$$

Children can pull a slip of paper containing a set of "magic" numbers with their combinations on the back, and test one another or themselves on relating the numbers four ways. 
h. Game; "Number Families:" A child is chosen to go to the front of the room, and announce his "first" and "last" number names (e.g., "My first name is 6; my last name is 9"). He then asks the class "What is my middle name?" First child to give his middle name may be the next "mystery person." This game can be given added color by having each "mystery person" go first. behind a screen or door where he chooses a hat to wear from a provided selection. A simple costume technique such as this provides a role play outlet for some students who might feel inhibited about taking part, and provides added interest for all students.

\section{The Growth of Reasoning Skills}

\section{A. Understanding Cause and Effect}

1. Behavior Illustrations

a. Child makes appropriate assumptions about psychological intention in explaining stories or real life situations ("The clock ran fast because it was broken").

b. Child asks pertinent questions about the specific cause of things.

c. Child gives sensible and evaluative reasons in response to "why do you think" type questions about stories and experiences (e.g., Zoo animals are kept in cages..." because they're too dangerous").

d. Child understands the notion of the conditional (if... then) possibility (e.g., "If it rains, we will read a story") (42).

2. Instructional Suggestions

a. Make a "Story Starter" box in which some "what if" starters are kept, each on a separate card. Children may individually select a card that interests them and write and illustrate a short story about that topic.

b. Class or small group activity: blending imagination with logic in contributing to the sequence of a story, using a "Magic Book" as a vehicle. Any jacket of an old book that has had its pages torn out, and is decorated inside and out, can suffice as a "magic book." The teacher carefully opens the book with no pages and begins a story. The book is passed on to a child, then from child to child, each making a contribution that can be as nonsensible as he wishes, just so that it in some way logically relates to the preceding sequence of statements offered by the other children. 
c. "Make A Sentence" game: child draws one card, each with a word printed on it, from all of a series of small boxes. One box contains words such as "may," "the," "this," and other words which could begin a sentence. Another box contains only names of things, and another, "action words." Hence the child cannot help but get all the components necessary for a logically constructed sentence. It is up to the child to put the cards in logical sequence at his desk. Since the selection of cards is based on chance, the child may end up with a statement such as "the wig sings," which makes this activity all the more interesting and fun. After the child has checked with another child about the order in which he has laid out the cards, he then copies the sentence on the bottom part of a paper, capitalizing and supplying the period, and illustrates the sentence.

\section{B. Reasoning By Association}

1. Behavior Illustrations

a. Child relates new ideas to concrete experiences of his own.

b. Child can tell a story about a picture, logically associating the ideas and elements in the picture.

c. Child applies story plots or morals to real life situations, making sense out of appropriate parallels (e.g., "Sandra is like Goldilocks--she ate everybody's cookies").

d. Child spontaneously associates two meanings with a word (e.g., "Trunk is on an elephant and a tree") (42).

2. Instructiona1 Suggestions

a. Association game: "How are and alike?" This can be played verbally with a group; individual children could also fold a sheet of paper in half, draw two things they can name that they perceive as alike in some way, and ask at the bottom of their picture (filling in the blanks) "How are and alike? For one answer, consult Joseph."

Sheets could be posted up on a bulletin board.

b. Ask, "How do these words go together?" Have written on the board two words, such as "tootsie roll" and "dentist." Another similar association technique would be to provide a list of words on a chart or board, and then ask "What words can you find in this list that could have something to do with a ?" 
c. Ask, "There is one secret word in this list that does not belong with the others. Who can find it?" Make the series of words as valuable as possible from the standpoints of vocabulary and concept building. One series might be: peanutbutter, bread, lettuce, jam, macaroni, butter. An overhead projector could work well with this activity; as series of words are projected, teams could play "beat the clock," a point being earned for the team first to find which word "does not fit."

d. "What's My Word?" Teacher chooses a volunteer who has a word for the other children to guess. He whispers his word to the teacher, then allows the class to ask questions, such as: what does it start with; does it name something that is alive; what does it rhyme with; does it name something that is bigger than you, etc. First child to guess the word may be next, or may choose someone who is ready with another word. (As letter clues, or a clue about how many letters the secret word has are given, these can be written on the board. When someone guesses the word, it can be written on the board for added reading reinforcement).

e. Post a weekly "research" question on the board, such as, "What are all the different ways you could use a tin can?" Place a box with a slot in it underneath the question. At the end of the week, open the box, discuss the answers found, and elicit additional associations from the class. Students could draw pictures of all the ways they could use an item like this, showing in their pictures what they changed about the can (or whatever) for each use; paper upon which drawings are made could be folded into parts, one part for each use, and each section could be labelled according to use. An association activity such as this could be related to a particular unit of study, such as community helpers (e.g., "What are all the jobs you can think of when you think of a candle?")

\section{Reasoning By Inference}

1. Behavior Illustrations

a. Child notices consistencies and inconsistencies in people's behavior and is able to go beyond these observations to make an inference (e.g., "The teacher chose George twice, she must have made a mistake"). 
b. Child infers certain logical relationships of the type:

$A=B, B=C$, therefore $A=C$ or

A B, B C, therefore A C

(e.g., "If your box won't fit through the door, then mine won't--it's bigger than yours").

c. Child anticipates the ending of a story or what comes next.

d. Child relates events he has heard about and tries to reach a conclusion (e.g., "If Lincoln and Washington are both dead now, does that mean they lived at the same time?") (42).

2. Instructional Suggestions

a. "Twenty Questions"

b. Read a paragraph and ask teams for the titles they think would be best, and why. For added "spice," each team could secretly decide and write its title down on a "secret ballot." Ballots could be unfolded and read by a "nonpartisan" student. Class discussion would follow about why or why not they think a certain title appropriate.

c. Show a picture to the class or to an individual child. Ask for all the questions that could be asked... questions about parts of the picture, all of the picture, and of the story the picture tells (picture could be one depicting an episode of a story the students have read or heard together). To assess levels of development of inferential reasoning, ask for questions about the picture that could not be answered merely by looking at the picture (e.g., if the picture was about the "Three Little Pigs," the question "who is trying to blow the straw house down" would not suffice in this instance, whereas "What do you think the pig in the straw house is thinking about" would reveal a greater developed inferential, cause-effect reasoning). 


\section{BIBLIOGRAPHY}

1. Aaron, Ira A. "The Relationship of Selected Measures to Spelling Achievement at the Fourth and Eighth Grade Levels." Journal of Educational Research, Vo1. 53, No. 4, December, 1959.

2. Aaron, Ira A. "What Teachers and Prospective Teachers know About Phonics Generalizations," Journal of Educational Research, Vo1. 53, No. 9, May, 1960.

3. Adams, Georgia Sachs, Measurement and Evaluation in Education, Psychology, and Guidance, Holt, Rinehart and Winston, New York, 1964.

4. Ausube1, David P., "A Teaching Strategy for Culturally Deprived Pupils," Education in the Metropolis, Harry L. Miller and Marjorie B. Smiley, eds., The Free Press, New York, 1967.

5. Bagley, W. C., Determinism in Education, Warwick and York, Inc., Baltimore, 1925.

6. Baldwin, James, "A Letter from Harlem," Education in the Metropolis, Harry L. Miller and Marjorie B. Smiley, eds., The Free Press, New York, 1967.

7. Barbe, Walter B., "Identification and Diagnosis of the Needs of the Educationally Retarded and Disadvantaged," The Educationally Retarded and Disadvantaged, Paul A. Witty, ed., The University of Chicago Press, Chicago, 1967.

8. Barzun, Jacques. The Teacher In America. Atlantic Month1y Press, 1945.

9. Bay, Christian, "A Social Theory of Intellectual Development," Social Foundations of Education, Jonathan C. McLendon, ed., The Macmillan Co., New York, 1966.

10. Becker, Howard S., "Social-Class Variations in the Teacher-Pupil Relationship," Education and Society, W. W. Kallenbach and H. M. Hodges, Jr., eds., Charles E. Merrill Books, Inc., Columbus, Ohio, 1963.

11. Bloomer, Richard H., "An Investigation of an Experimental First Grade Phonics Program," Journal of Educational Research, Vo1. 53, No. 5, January, 1960.

12. Bontemps, Arna, Story of the Negro, Alfred A. Knopf, New York, 1948.

13. Bowyer, Helen, "England and America Compete: Phonemic Readers for First Graders," Phi Delta Kappan, Vo1. XIIV, No. 3, December, 1962.

14. Cervantes, Lucius F., "Family Background, Primary Relationships, and the High School Dropout," Society and Education, R. J. Havighurst, B. I. Newgarten, and Jacqueline M. Falk, eds., Allyn and Bacon, Inc. 
15. Clark, Willis W., "Boys and Girls -- Are There Significant Ability and Achievement Differences," Phi Delta Kappan, Vol. XLI, No. 2, November, 1959.

16. Clymer, Theodore, "The Utility of Phonic Generalizations in the Primary Grades," The Reading Teacher, Vol. 16, No. 4, January, 1963.

17. Coles, Robert, "The Poor Don't Want to be Middle Class," Education in the Metropolis, Harry L. Miller and Marjorie B. Smiley, eds., The Free Press, New York, 1967.

18. Council for Basic Education Bulletin, Mortimer Smith, ed., Vol. 13, No. 10, June, 1969.

19. Daniel, Walter G., "Some Effects of Deprivation on Intelligence, Achievement, and Cognitive Growth," The Journal of Negro Education, Vo1. 36, No. 1, Winter, 1967.

20. Davis, W. Allison, and Havighurst, Robert J., "The Measurement of Mental Systems (Can Intelligence Be Measured?)," Scientific Monthly, Vo1. 4, No. 18, April, 1948.

21. Downie, N. M., Fundamentals of Measurement: Techniques and Practices, Oxford University Press, New Yonk 1967.

22. Durost, Walter N., and Prescott, George A., Essentials of Measurement for Teachers, Harcourt, Brace and Wor1d, Inc., New York, 1962.

23. Eames, Thomas H., "Summary of a Comparative Study of Eye Conditions Among Reading Failures and Unselected Pupils," Journal of Education Vo1. 141, No. 3, February, 1959.

24. Educational Measurement, E. F. Lindquist, ed., American Council on Education, Washington, D. C., 1951.

25. Encyclopedia of Educational Research, Chester W. Harris, Ed., Macmillan Co., New York, 1960.

26. Friedenberg, Edgar Z., "An Ideology of School Withdrawal," Social Foundations of Education, Jonathon C. McLendon, ed., The Macmillan Co., New York, 1966.

27. Gage, N. L., ed. Handbook of Research on Teaching, American Educational Research Association, Chicago: Rand McNally and Company, 1963.

28. Gillin, John, "Educators and Social Class," Social Foundations of Education, Jonathon C. McLendon, ed., The Macmillan Co., New York, 1966. 
29. Ginzberg, E1i, The Negro Potential, Columbia University Press, New York, 1956.

30. Harvard Educational Review, editors' comment, Vo1. 39, No. 1, Winter, 1969.

31. Havighurst, Robert J., "Elements Influencing Stratification in Society and in Education," Social Foundations of Education, Jonathon C. McLendon, ed., The Macmiljan Co., New York, 1966.

32. Hildreth, Gertrude, "Early Writing as an Aid to Reading," The Education Digest XXVIII, No. 7, March, 1963.

33. Jensen, Arthur R., "How Much Can We Boost IQ and Scholastic Achievement," Harvard Educational Review, Vo1. 39, No. 1, Winter, 1969.

34. Kagan, Jerome S., and Hunt, J. McV.; Crow, James F.; Bereiter, Carl; Elkind, David; Cronbach, Lee J.; Brazziel, William F., "How Much Can We Boost IQ and Scholastic Achievement?" A Discussion, Harvard Educational Review, Vo1. 39, No. 2, Spring, 1969.

35. Kardiner, Abram, and Ovesey, Lione1, "The Social Environment of the Negro," Knowing the Disadvantaged, Part I, Staten, W. Webster, ed., Chandler Publishing Co., San Francisco, 1966.

36. Kasdon, Lawrence M., "Early Reading Background of Some Superior Readers Among College Freshmen," Journal of Educational Research, Vo1. 52, No. 4, December, 1958.

37. Keller, Suzanne, "The Social World of the Urban Slum Child," Education in the Metropolis, Harry L. Miller and Marjorie B. Smiley, eds., The Free Press, New York, 1967.

38. Kimbra11, Solon T., "Cultural Influences Shaping the Role of the Child," Social Foundations of Education, Jonathon C. McLendon, Ed., The Macmillan Co., New York, 1966.

39. Klineberg, Otto, Characteristics of the American Negro, Harper and Brothers Publishers, New York, 1944.

40. Kozo1, Jonathon, "Ha1ls of Darkness in the Ghetto Schools," Harvard Educational Review, Vo1. 37, No. 3, 1967.

41. Larson, Robert E., and Selland, Cynthia T., "A Comparison of Reading Ages with Mental Ages," Journal of Educational Research, Vol. 52, No. 2, October, 1958. 
42. Let's Look at First Graders," Cooperative Test Series Specimen Set, Educational Testing Service, Board of the City of New York, 1965.

43. Lindval1, C.M., Testing and Evaluation: An Introduction, Harcourt, Brace and World, Inc., 1961.

44. Manning, Walton, "Negro Education," series of five articles, Register and Tribune Syndicate, Des Moines, Iowa, 1962.

45. Manning, Walton, "What You Should Know About Tests," special series of six articles, Register and Tribune Syndicate, Des Moines, Iowa Summer, 1961.

46. Mayer, Kurt B., "The Changing Shape of the American Class Structure," Society and Education, R. J. Havighurst, B. L. Newgarten, and Jacqueline M. Falk, eds., Allyn and Bacon, Inc., Boston, 1967.

47. McCreary, Anne Phillips, "Intergroup Relations in the Elementary School," Education and Society, W. W. Kallenbach and H. M. Hodges, Ir., eds., Charles E. Merrill Books, Inc., 1963.

48. Miller, Harry L., and Smiley, Marjorie B., eds., Education in the Metropolis, The Free Press, New York, 1967.

49. Morgan Jr., Elmer F., "Efficacy of Two Tests in Differentiating Potentially Low from Average and High First Grade Achievers," Journal of Educational Research, Vo1. 53, No. 8, April, 1960.

50. Neville, Donald, "A Comparison of the Wisc Patterns of Male Retarded and Non-Retarded Readers," Journal of Educational Research, Vo1. 54, No. 5, January, 1961.

51. Newgarten, Bernice L., "Social Class and Friendship Among School Children," Society and Education, R. J. Havighurst, B. L. Newgarten, and Jacqueline M. Falk, eds., Allyn and Bacon, Inc., Boston, 1967.

52. Newmann, Fred M. and Oliver, Donald W., "Education and Community," Harvard Educational Review, Vo1. 37, No. 1, Winter, 1967.

53. Otto, Wayne, et a1, Prototypic Guide to Reading Skill Development In the Elementary School, Wisconsin Research and Development Center for Cognitive Learning, University of Wisconsin, 1967.

54. Palmore, Erdman, "Factors Associated with School Dropouts and Juvenile Delinquency Among Lower Class Children," Society and Education, R. J. Havighurst, B. L. Newgarten, and Jacqueline M. Falk, eds., Allyn and Bacon, Inc., Boston, 1967. 
55. Parsley Jr., K. M. and Powe11, Marvin; "Relationships Between the Lee-Clark Reading Readiness Test and the 1937 Revision of the Stanford-Binet Intelligence Test, Form L," Journal of Educational Research, Vo1. 54, No. 8, April, 1961.

56. Parsons, Talcott, "The School Class as a Social System: Some of Its Functions in American Society," Society and Education, R. J. Havighurst, B. L. Newgarten, and Jacqueline M. Falk, eds., Allyn and Bacon, Inc., Boston, 1967.

57. Peterson, John, "The Researcher and the Underachiever: Never the Twain Shall Meet," Phi Delta Kappan, Vo1. XLIV, No. 8, May, 1963.

58. Reissman, David, "The Culturally Deprived Child: A New View," Social Foundations of Education, Jonathon C. McLendon, ed., The Macmillan Co., New York, 1966.

59. Riessman, Frank, "One in Three," Student, Schoo1, and Society, John A. Dah1, Marvin Laser, Robert S. Cathcart, and Fred H. Marcus, eds., Chandler Publishing Co., San Francisco, 1964.

60. Roucek, Joseph S., "Milestones in the History of the Education of the Negro in the United States," Social Foundations of Education, Jonathon C. McLendon, ed., The Macmillan Co., New York, 1966.

61. Salisbury, Robert H., "Schools and Politics in the Big City," Harvard Educational Review, Vol. 37, No. 3, Summer, 1967.

62. School and Society, I. L. Kande1, ed., Vo1. 75, No. 1947, April 12,1952 .

63. Shuey, Audrey Mary, The Testing of Negro Intelligence, J. P. Be11 Co., Inc., Lynchberg, Virginia, 1958.

64. Siebert, Fred S., "The Role of Communication in Different Forms of Society," Social Foundations of Education, Jonathon C. McLendon, ed., The Macmillan Co., New York, 1966.

65. Silberman, Charles E., "The City and the Negro," Education in the Metropolis, Harry L. Miller and Marjorie B. Smiley, eds., The Free Press, New York, 1967:

66. Smith, Mortimer, "The Battle Over National Assessment," Council for Basic Education Bulletin, Vo1. 11, No. 6, February, 1967.

67. Stendler, Celia Burn, "Class Biases in the Teaching of Values," Education and Society, W. W. Kallenbach and H. M. Hodges, Jr., eds., Charles E. Merrill Books, Inc., Columbus, Ohio, 1963. 
68. Stodolsky, Susan S., and Gerald Lesser, "Learning Patterns in the Disadvantaged," Harvard Educational Review, Vol. 37, No. 4, Fall, 1967.

69. The Impact and Improvement of School Testing Programs, National Society for the Study of Education, Warren G. Findley, ed., University of Chicago Press, 1963.

70. Time, "Race and Ability," Essay, Vo1. 90, No. 13, September 29, 1967.

71. Townsend, Agatha, "What Research Says to the Reading Teacher" The Reading Teacher, Vo1. 15, No. 1, September, 1961.

72. Travers, John F., "The Fascination of Phonics," Education, Vol. 84, No. 1, September, 1963.

73. Wade, Durlyn E., "Social Class in a Teachers College," Education and Society, W. W. Kallenbach and H. M. Hodges, Jr., eds., Charles E. Merrill Books, Inc., Columbus, Ohio, 1963.

74. Waller, Willard, "The Sociology of the Schoo1," Education and Society, W. W. Kallenbach and H. M. Hodges, Jr., eds., Charles E. Merrill Books, Inc., Columbus, Ohio, 1963.

75. Warner, Lloyd W., "Social Class and Personality Development," Social Foundations of Education, Jonathon C. McLendon, ed., The Macmillan Co., New York, 1966.

76. Wattenberg, William, et al., "Social Origin and Teaching Role -Some Typical Patterns," Society and Education, R. J. Havighurst, B. L. Newgarten, and Jacqueline M. Falk, eds., Allyn and Bacon, Inc., Boston, 1967.

77. Webster, Staten W., Knowing the Disadvantaged, Part I, Chandler Publishing Co., San Francisco, 1966.

78. Webster, Statten W., Knowing the Disadvantaged, Part II, Chandler Publishing Co., San Francisco, 1966.

79. Wolff, Max, "Segregation in the Schools of Gary, Indiana," Society and Education, R. J. Havighurst, B. L. Newgarten, and Jacqueline M. Falk, eds., Allyn and Bacon, Inc., Boston, 1967. 
APPENDIX

LIST OF CITIES FROM WHICH TESTING INFORMATION WAS SOUGHT

\author{
Atlanta, Georgia \\ Berkeley, California \\ *Birmingham, Alabama \\ Boise, Idaho \\ *Boston, Massachusetts \\ Chicago, Illinois \\ *Cleveland, Ohio \\ Columbus, Ohio \\ Dallas, Texas \\ *Denver, Colorado \\ Detroit, Michigan \\ Houston, Texas \\ Indianapolis, Indiana \\ Jackson, Mississippi \\ Kalamazoo, Michigan \\ Long Beach, California \\ Milwaukee, Wisconsin \\ Nashville, Tennessee \\ New York City, New York \\ Newark, New Jersey \\ Palo Alto, California \\ Philadelphia, Pennsylvania \\ Phoenix, Arizona \\ *Raleigh, North Carolina \\ *Richmond, Virginia \\ St. Louis, Missouri \\ St. Paul, Minnesota \\ *Salt Lake City, Utah \\ Seattle, Washington \\ Tallahassee, Florida
}

*Did not respond to the request. 